\title{
Realizing Surface Amphiphobicity using 3D Printing Techniques: A Critical Move Towards Manufacturing Low-Cost Reentrant Geometries
}

\author{
Hamza Shams ${ }^{1,2}$, Kanza Basit ${ }^{1}$, Muhammad Ali Khan², Sajid Saleem ${ }^{1}$, Asif Mansure ${ }^{1}$ \\ 1. Industrial and Manufacturing Engineering Department, National University of Sciences and \\ Technology (NUST), Islamabad, Pakistan \\ 2. School of Aerospace, Transport and Manufacturing, Cranfield University, Cranfield, United \\ Kingdom
}

Corresponding Author: Hamza Shams (hamza.shams@cranfield.ac.uk)

\begin{abstract}
Superamphiphobic surfaces are obtained by lowering the surface energy through changes in surface geometry. These changes can be designed on the surface, altering its wettability, in turn rendering it superamphiphobic. The main geometrical entities behind this phenomenon are reentrant geometries which prevents the solid-liquid interface tension from breaking, thereby resulting in contact angles greater than $150^{\circ}$. The science behind modelling and manufacturing of these reentrant geometries is well established apart from manufacturing them via extrusion based 3-Dimensional printing processes.
\end{abstract}

This review paper in identifying this scope, summarizes various characterization parameters for surface wettability followed by identifying the role of surface reentrant geometries to introduce superamphiphobicity in polymers. In defining the current state of research in this domain, this compendium identifies that extrusion based 3-Dimensional processes can successfully be used for creation of superamphiphobic surfaces. However, this usually involves addition of a secondary agent which diminishes the role of the surface reentrant geometry. Therefore, a clear route based on extrusion based 3-Dimensional printing of surface reentrant geometry to limit dependency on base substrate has not been fully explored. This opens avenues for testing of new filament-based polymeric materials like PVC and PETG, whose surface properties can be enhanced using reentrant geometries.

Keywords: Reentrant Geometry, Superamphiphobicity in Polymers, 3D Printing, Wetting Angle

\section{Introduction}

Developments pertaining to combined repellency against water and oil using surfactants dates back to 1980 s [1]. However, it has been well established that a combination of surface texturing; which also results in changes to surface roughness, and modification of surface chemistry; to induce new interfacial properties, can be attributed as the formative principles behind modifying surface wettability [2-8]. Changes in surface wettability can result in the surface becoming superamphiphobic [9].

An amphiphobic surface is defined in terms of repellency against both polar (e.g. water) and non-polar (e.g. oil) liquids and one which forms a wetting angle (contact angle) that is greater than $90^{\circ}$ with the liquid. Similarly, superamphiphobic surfaces comparable to superhydrophobic surfaces are defined in terms of the wetting angle being greater than $150^{\circ}[10-13]$. Superamphiphobicity is a result of low surface energy of the solid-liquid-vapor system formed at the surface [14,15]. Successful superamphiphobic surfaces also exhibit three more characteristics in addition to those listed above [16], these are a) a Low Contact Angle Hysteresis (CAH) to maximize liquid mobility [17], b) high critical 
pressure value [18] over which the surface remains stable, and c) a high energy barrier to failure [19] which prevents the liquid from completely wetting the surface grooves.

The key point of this surface characteristic is that it is not material specific [20]. Therefore, based on the specific applications relating to self-cleaning [21], anti-fouling [22], anti-icing [23], anti-corrosion [24], drag reduction [25] and many others, superamphiphobicity may be introduced where metals, polymers and ceramics are used as the base substrates [26]. Another key area of application for superamphiphobic surfaces lies in the self-driving, anti-gravity unidirectional transport mechanisms $[27,28]$ especially in the design of microfluidics transportation where pumping liquids using an external source may not be possible. This kind of surface modification plays a vital role in preserving and enhancing long-term utility of materials where surface coating is not an option and the intrinsic properties of base substrate are required [12]. Some polymers such as polycaprolactone (PCL) [29], polytetrafluoroethylene (PTFE) [30], Polydimethylsiloxane (PDMS) etc. [31,32] have functional groups which naturally exhibit superhydrophobic characteristic. However, where this may not be possible, surfaces can be selectively modified to exhibit self-cleaning behaviour [33-37].

As previously discussed, this requires adding distinctive modifications on the surface structure of the polymer which enables the polymeric chains to exhibit properties which may or may not be characteristic to them $[38,39]$. Numerous methods for their fabrication with wide ranging results are available throughout the literature [40-42]. While these methods are highly repeatable, and some can be transformed from lab-scale environment into full-scale manufacturing environment [43-45], their utility remains low due to the process complexity and difficulty in achieving complex surface geometries $[13,46]$. Therefore, new methods which can ease the difficulty in manufacturing of these complex features are being worked upon.

Additive Manufacturing or 3D Printing as it is commonly called, provides a cost-effective solution to the problem of fabricating complex surface geometries to induce superamphiphobicity, which is otherwise not possible with traditional manufacturing techniques[47-49]. 3D Printing techniques with their wide range of available materials[50], direct CAD to product translation and small setup requirements allow for creation of accurate and repeatable geometrical features which are a requirement of these newfound applications [51].

Despite recent advents in 3D printing techniques, the utility of extrusion based additive manufacturing processes remain high [47]. This is because of the ease with which process parameters for extrusionbased processes can be selectively modified for specific materials $[52,53]$. Due to the subsequent development in extrusion-based techniques, multiple polymeric materials of high commercial importance are readily available for use as a raw material $[47,54,55]$. With an understanding, that superamphiphobic interaction is not material specific, these extrusion-based techniques can be readily used to develop complex surface geometries on these materials for enhancement of surface properties.

To establish the utility of these extrusion-based 3D printing techniques for creating superamphiphobic interaction, we first begin with an understanding of the basic measurements for characterization of superamphiphobic surfaces. This is followed by defining the role of surface geometry to exhibit superamphiphobicity and how extrusion-based additive manufacturing processes have been successfully used for this purpose. The article concludes on findings from the literature for possible future work in this area.

To move this discussion forward, we start with the definition of the wetting angle as the foremost criterion for characterizing a truly superamphiphobic surface. 


\section{Wetting Angle}

The wetting angle or contact angle is a measure of surface wettability which is defined as the tendency of a liquid to spread on or adhere to a solid surface in the presence of other immiscible fluids [56]. The wetting angle for superamphiphobic interaction is characterized using the Wenzel and Cassie-Baxter Models which define the contact mechanics behind liquid-air interface formed at the surface $[57,58]$. The principal behind the two models is the Surface Energy; measured as energy per unit area, which results from non-symmetric bonding of atoms/molecules found on the surface directly in-contact with the vapor [59]. The two models are based on the contact angle model formulated by Thomas Young [14] whose initial inspiration came from Galileo's work titled Discorso intorno alle Cose che Stanno in su l'Acqua of the $17^{\text {th }}$ Century [60]. The Young's Contact Model is illustrated in Figure 1 and defined by Equation 1.

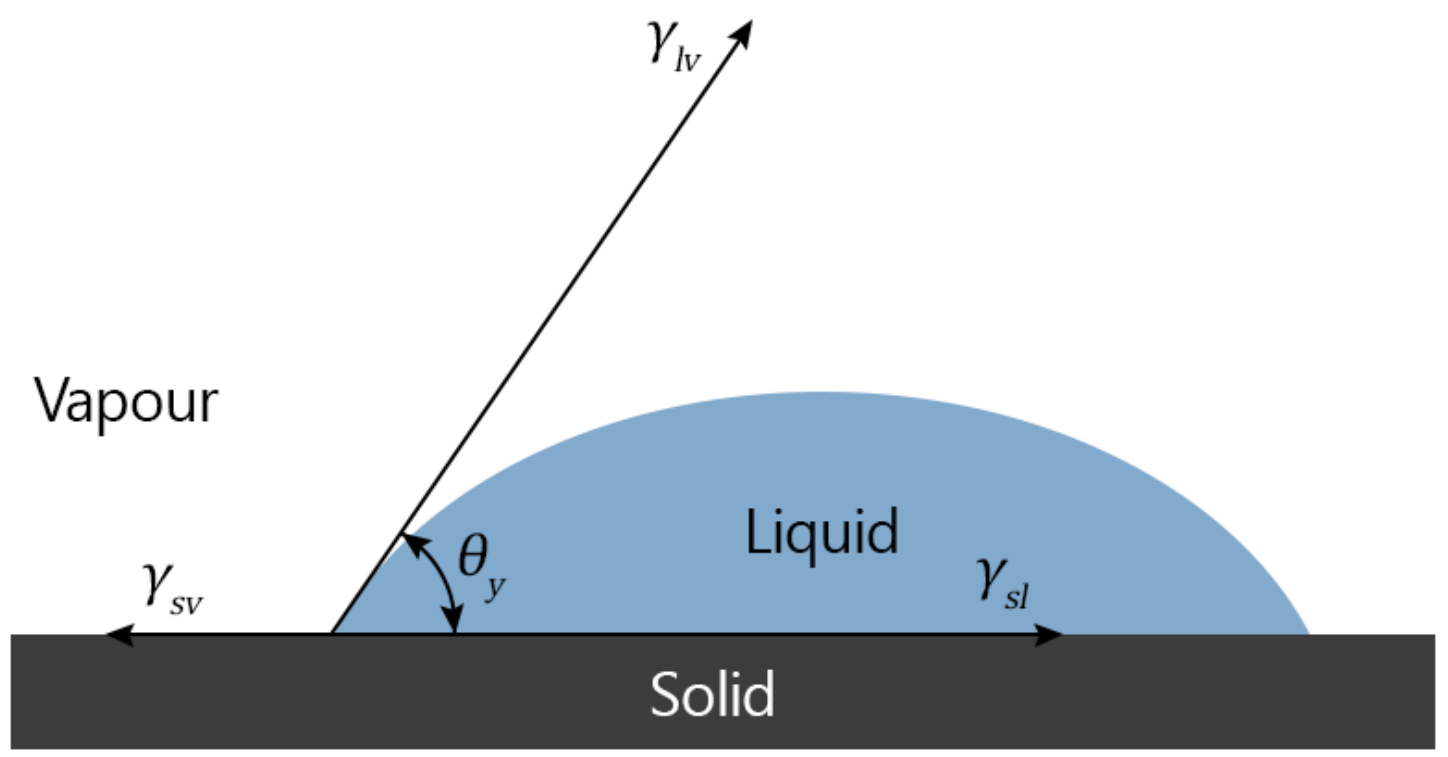

Figure 1: Young's Static Contact Angle Model

$$
\cos \theta_{y}=\frac{\gamma_{s v}-\gamma_{s l}}{\gamma_{l v}}
$$

where $\theta_{y}$ is the wetting angle (contact angle) while $\gamma_{s v}, \gamma_{s l}$ and $\gamma_{l v}$ are the solid-vapor interface tension, solid-liquid interface tension and liquid-vapor interface tension, respectively.

Young's first presentation of the solid-liquid equilibrium opened gateways for scholars to further develop their understanding on this concept, where the wetting angle became the basis for defining the wettability or spread of the liquid in the interface. However, this model has one characteristic limitation, which is that it predicts contact angle over an extremely smooth surface (zero surface roughness) which is not representative of any real-life surface [38]. Building up on this theory, Wenzel modelled the role of surface roughness in altering the contact angle and used to introduce a roughness ratio, $\mathrm{R}$ defined as the ratio of the actual surface area of the solid-liquid interface to the projected or nominal surface area (where the liquid is actually in contact with the liquid) as shown in Figure 2 and Equation 2 [57]. For ideal scenario where the surface becomes flat or has zero roughness, $R$ is equal to 1 (Young's Contact Model), while for all other cases R is always greater than 1. 


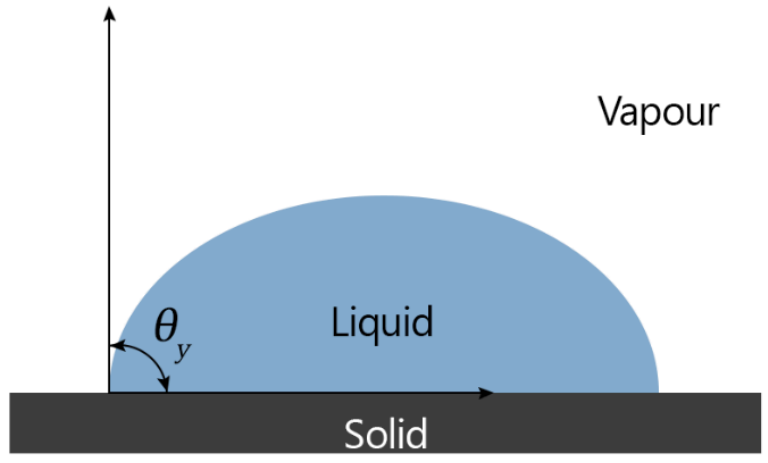

(a)

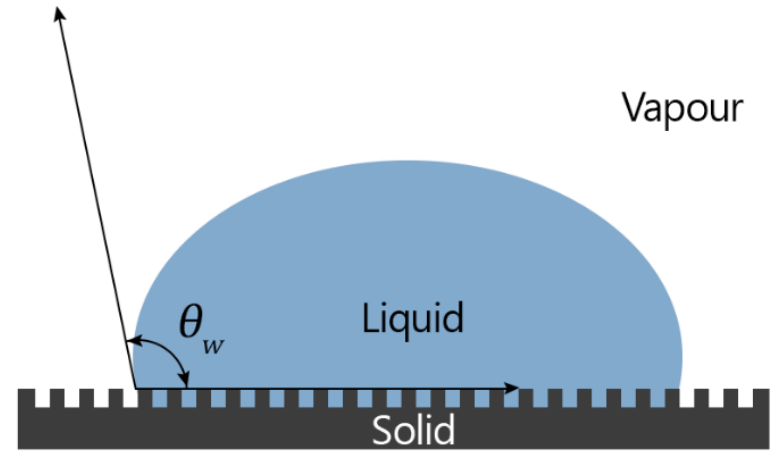

(b)

Figure 2: Wenzel Static Contact Angle Model where, a) shows the Young's Static Contact Angle and b) shows the changed Wenzel Contact Angle due to surface roughness where the liquid phase has completely penetrated the surface grooves.

$$
\cos \theta_{w}=R \cos \theta_{y}
$$

where $\theta_{w}$ is the Wenzel contact angle of the liquid droplet on the rough surface, $\theta_{y}$ is the equilibrium contact angle on the smooth surface of the same material. By consideration of this surface roughness, the model assumes that the liquid has penetrated the grooves of the rough surface, thereby being in complete contact with the solid surface. As per theory, this means that the contact angle at Young's state and contact angle at Wenzel state will be different. If the contact angle is hydrophobic in the Young's state, then it will become more hydrophobic in the Wenzel state and if the contact angle is hydrophilic in the Young's state then it will become more hydrophilic in the Wenzel state due to the effect of surface roughness [61]. The Wenzel model pose limitation in that it only accounts for the presence of two phases that is solid and liquid at the contact line, where the solid surface is also taken to be homogenous $[62,63]$. The Cassie-Baxter model [58] considers the presence of the third phase, that is vapour inside the grooves underneath the liquid which restricts complete wetting of the solid surface as shown in Figure 3. The model is defined based on the following Cassie-Baxter Equation (Equation 3):

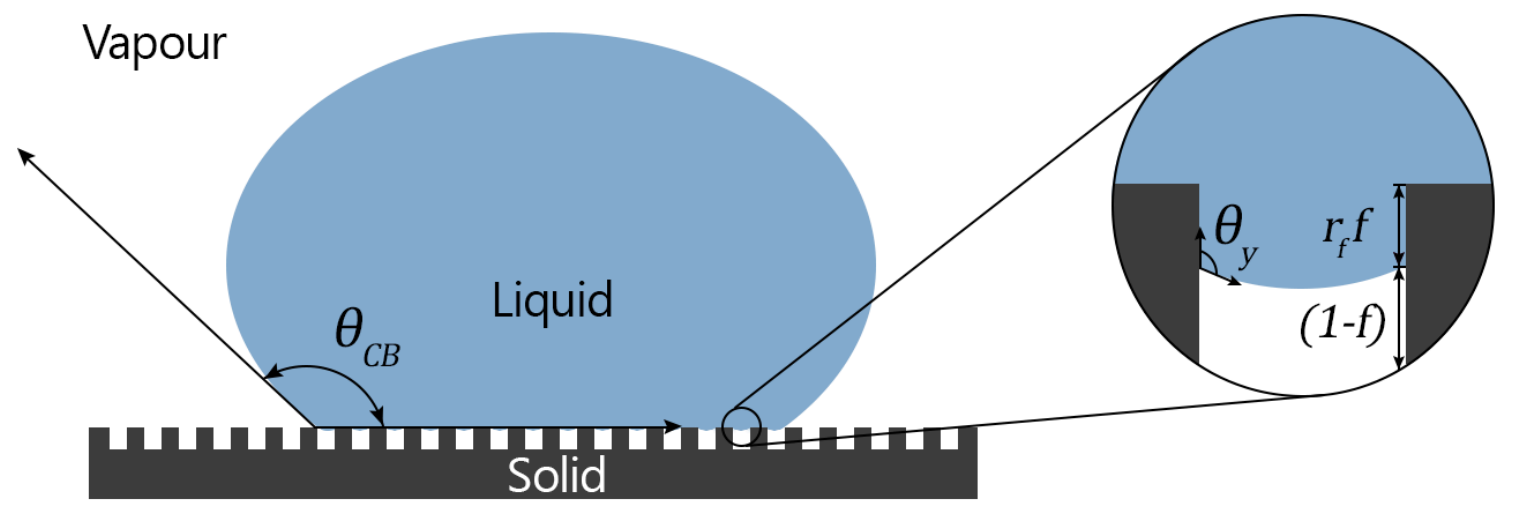

(a)

(b)

Figure 3: Cassie-Baxter Static Contact Angle Model where, a) shows the Cassie-Baxter state where the liquid droplet rests above the surface due to entrapped air in the surface grooves and b) shows the governing parameters behind the CassieBaxter model of Equation 3.

$$
\cos \theta_{C B}=r_{f} f \cos \theta_{y}-(1-f)
$$


where $r_{f}$ is the local roughness ratio, $f$ is the fraction of the projected area of the liquid droplet in contact with the solid surface $(0 \leq f \leq 1), \theta_{y}$ is the contact angle between the liquid and the solid interface and $(1-f)$ is the area fraction of the liquid droplet in contact with air trapped in the pores of the rough surface.

It is appropriate to highlight here that while Cassie-Baxter Model is widely used to define a Superamphiphobic interaction, Young's Equation in its true form and Wenzel model are hardly ever used [64]. This is because of the limitation posed by Young's and Wenzel's model equations [65]. As mentioned earlier Young's equation can only be applied to a surface having zero roughness and the Wenzel model while catering for the surface roughness can only be applied to a truly homogenous surface. Only Cassie-Baxter model accounts for surface roughness and heterogeneity. However it is important to note that none of these models account for Contact Angle Hysteresis (CAH) [66], which is an important measurement parameter and is explained later on.

While literature on these 03 contact models is well-defined, evaluation of an analytical solution to find out an estimate of the Contact Angle using the model equations is a tedious task and is based widely on making assumptions [67-70]. However, at the same time empirical results for wetting angle can be easily obtained using Contact Angle measurement [71].

\section{Measurement of Wetting Angle}

\subsection{Static Contact Angle Measurement}

Measurement of contact angle can be conducted using an optical instrument such as a Contact Angle Meter which should be capable of photographing a liquid droplet having a volume of less than $20 \mu \mathrm{l}$ [72]. Nevertheless, some researchers claim that the ideal size of the liquid droplet should be less than $4 \mu \mathrm{l}$ [73-77], where for practical purposes, one should use a slightly bigger volume of liquid say up to $5 \mu \mathrm{l}$ and then allow sufficient time for the liquid to evaporate so that the droplet can reduce to this volume [73]. The contact angle is then obtained using a fitting technique such as ellipse fitting [78,79], circle fitting $[80,81]$, Young-Laplace fitting $[82,83]$, polynomial fitting $[84,85]$ and tangent searching mode $[86,87]$ techniques.

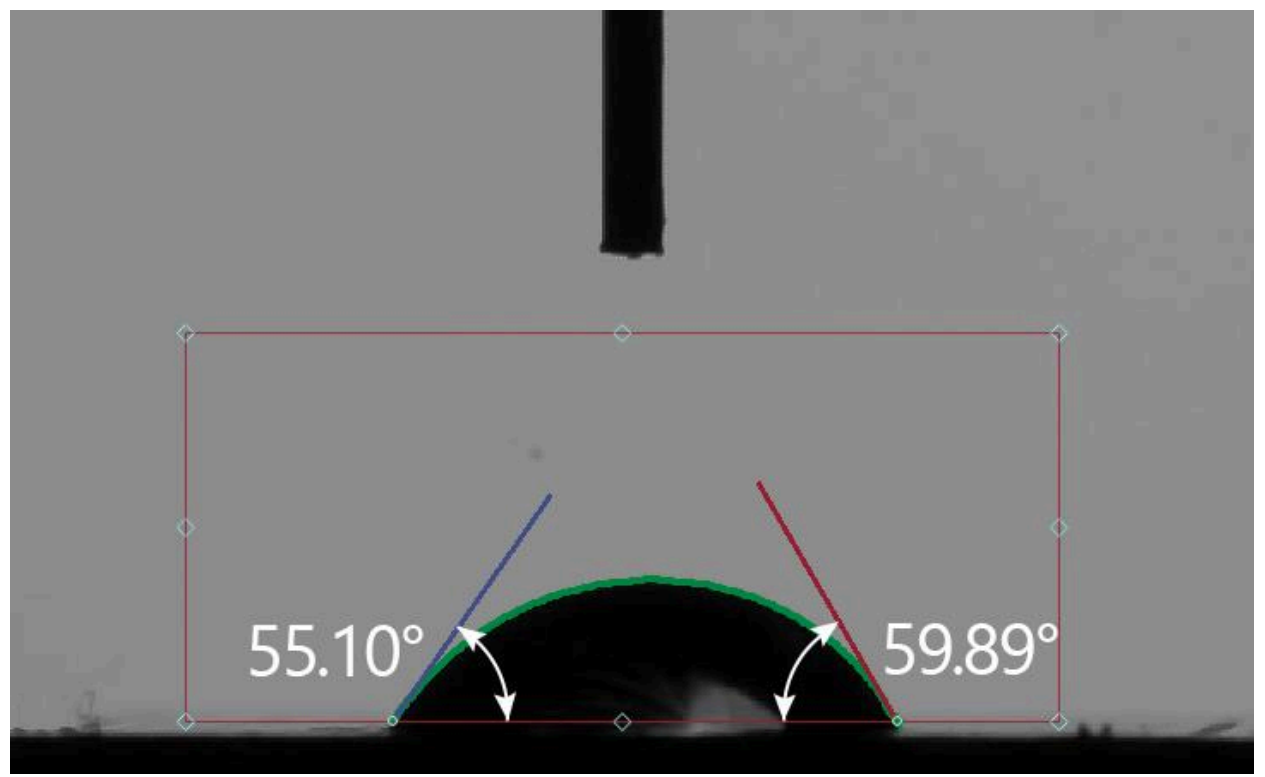

Figure 4: Left and right contact angles measured using Polynomial fitting technique on a $5 \mu$ droplet suspended over a flat 3D printed surface recorded and analysed using Oscilla Contact Angle Goniometer 
Figure 4 shows a standard contact angle measurement software screen with Polynomial fitting technique applied to the droplet shape to decipher contact angles in relation to the flat surface. Moreover, Table 1 provides a quick summary developed by F. Thomsen of KRÜSS GmbH [88] to decide for which fitting technique are applicable for measuring superamphiphobic interaction which depends on the listed parameters.

Table 1: Qualitative Summary for Selection of Curve Fitting Technique for Measurement of Contact Angle developed by F. Thomsen of KRÜSS GmbH (Original Table Truncated to Show Relevant Data)

\begin{tabular}{|l|c|c|c|c|}
\hline & Circle & $\begin{array}{c}\text { Conic } \\
\text { Section }\end{array}$ & Polynomial & $\begin{array}{c}\text { Young } \\
\text { Laplace }\end{array}$ \\
\hline Measuring Range & & & & \\
\hline $0-20^{\circ}$ & $\checkmark$ & & & \\
\hline $10-100^{\circ}$ & & $\checkmark$ & $\checkmark$ & $\checkmark$ \\
\hline $100-180^{\circ}$ & & & $\checkmark$ & $\checkmark$ \\
\hline
\end{tabular}

Therefore, as seen from the Table 1, for a true superamphiphobic interaction where contact angles are greater than $150^{\circ}$, Polynomial Fitting and Young-Laplace fitting techniques are more commonly used.

\subsection{Tilt Angle Measurement}

However, measurement of this static contact angle does not qualify for a surface to be truly superamphiphobic [89]. A true superamphiphobic surface should rapidly repel liquid without causing any significant distortion to the liquid droplet's bead-like shape [90]. In the Wenzel state the liquid droplet penetrates the grooves of the surface and adheres to them, causing measurable distortion to the droplet's shape and making it difficult to roll off upon tilting [91]. This change in droplet's shape upon tilting gives rise to advancing and receding angles as shown in Figure 5.

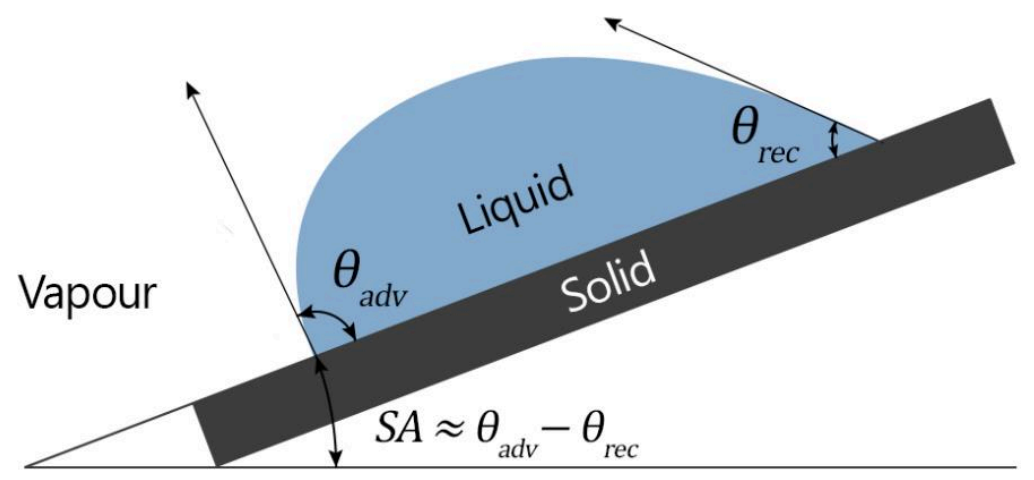

Figure 5: Measurement Method for Tilt (Sliding) Angle where Tilt Angle (SA) approximates to the difference of Advancing $\left(\boldsymbol{\theta}_{\text {adv }}\right)$ and Receding $\left(\boldsymbol{\theta}_{\text {rec }}\right)$ angles

This means that if the surface is truly superamphiphobic it should not allow the liquid droplet to adhere to it and hence the droplet should have small (almost zero) advancing and receding angles upon tilting [20]. Another way of measuring these angles is by slowly varying the volume of the liquid droplet and measuring the difference in the advancing and receding angles as the contact line expands and shrinks as shown in Figure 6. This measurement of droplet's adhesive behaviour gives rise to understanding of the second criterion which needs to be satisfied to characterize a superamphiphobic surface, termed as the Contact Angle Hysteresis [92]. 
(a)

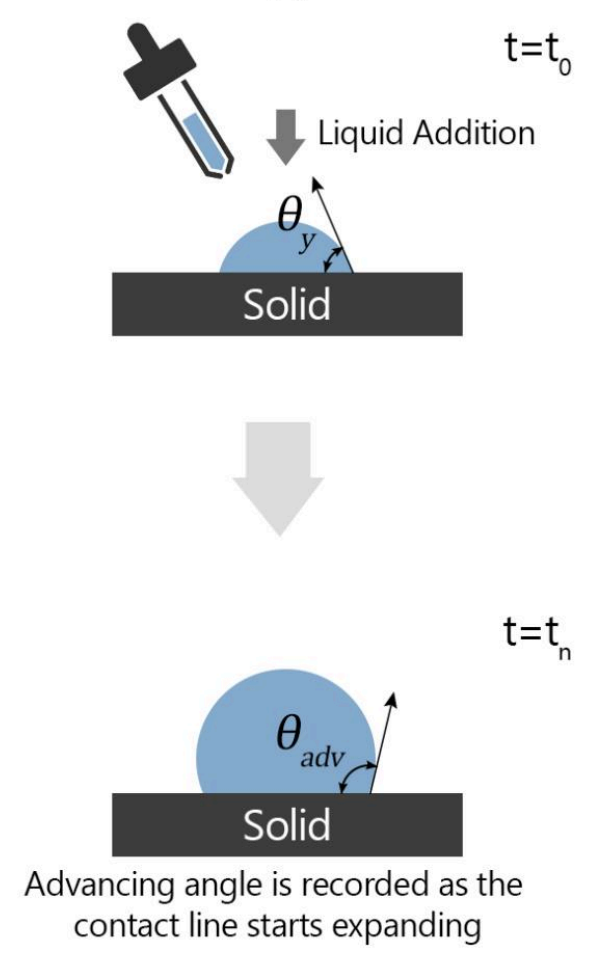

(b)
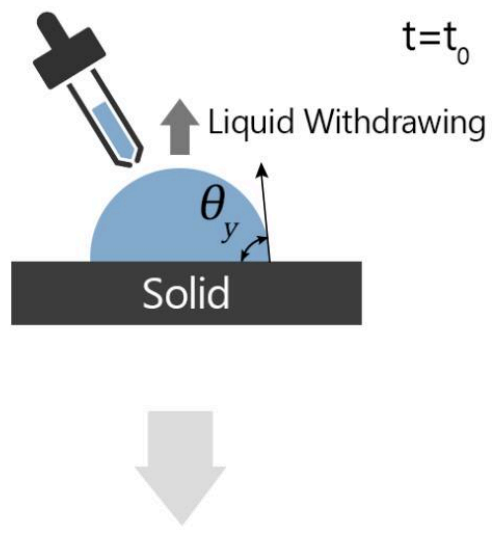

$t=t_{n}$

Solid

Receding angle is recorded as the contact line starts shrinking

Figure 6: Measurement Method for Advancing $\left(\boldsymbol{\theta}_{a d v}\right)$ and Receding $\left(\boldsymbol{\theta}_{r e c}\right)$ angles where a) shows that the $\boldsymbol{\theta}_{a d v}$ is recorded at the time where contact line starts expanding while $\theta_{\text {rec }}$ is recorded when the contact line starts shrinking due to addition and withdrawing of water volume from the droplet.

\subsection{Contact Angle Hysteresis}

Contact Angle Hysteresis or CAH for short is a measure of the difference between advancing and receding contact angles of a liquid droplet as it undergoes evaporation and cooling. [66]. CAH as discussed earlier is commonly used to quantify surface adhesion. A CAH angle of less than $10^{\circ}$ is termed as 'fakir' state [93-95], where vapor (air) is trapped in-between grooves and limits liquid penetration to wet the complete substrate. Examples of 'fakir' state are widely found in nature such as in the Lotus Leaf and Shark's Skin and therefore this effect is also sometimes referred to as the Lotus-leaf or Shark-skin effect [11,12]. A CAH angle of more than $10^{\circ}$ is referred to as the Rose-Petal effect, where the liquid completely penetrates and wets the grooves thereby resulting in higher adhesion of the liquid to the surface $[96,97]$. Low CAH values are indicative of self-cleaning behaviour and are therefore an important parameter for measurement while characterizing superamphiphobic surfaces [73].

Where $\mathrm{CAH}$ direct measurement through advancing and receding contact angles may be difficult, an alternate measurement of Tilt Angle (Sliding Angle) may be conducted. Tilt angle is a measure of the critical angle at which liquid tends to slide off when one end of the horizontal surface where the droplet is resting is lifted. While this does not equal the difference between the advancing and receding contact angles, it is usually very close to it as shown in Error! Reference source not found.. Tilt angle establishes an important parameter for characterization of superamphiphobic surfaces. A tilt angle of less than $10^{\circ}$ for both polar and non-polar liquids has been reported as a requirement for the surface to be termed as superamphiphobic $[40,73,98,99]$.

To summarize, Static Contact Angle Measurement, Tilt Angle Measurement and Contact Angle Hysteresis are the 03 most common measurement methods used in empirical study of characterizing a true superamphiphobic surface using $\mathrm{CA}$ and $\mathrm{CAH}$. 


\section{Role of Surface Geometry}

With the measurement parameters established, one must develop an understanding of the various physical structures which can be developed on the surface to induce superamphiphobic behaviour. This is important since as previously discussed, physical modification takes lead over chemical modification in demonstrating superamphiphobic behaviour [100] and can help in conversion of any non-amphiphobic surface into an amphiphobic one without any dependence of material $[34,39]$.

This physical modification is usually in the form of protrusions which enables formation of reentrant geometrical features on the surface which is a widely observed phenomenon in nature [101-104], where this behaviour limits sticking up of water and other contaminants on to the surface. Some examples include the Lotus Leaf effect [105-109], Shark skin effect [110-112], Gecko skin effect [113116] and Peach skin effect [117], named in accordance with the species on which it is observed. Figure 7, Figure 8, Figure 9 and Figure 10 show some high-resolution photographs of these structural features.
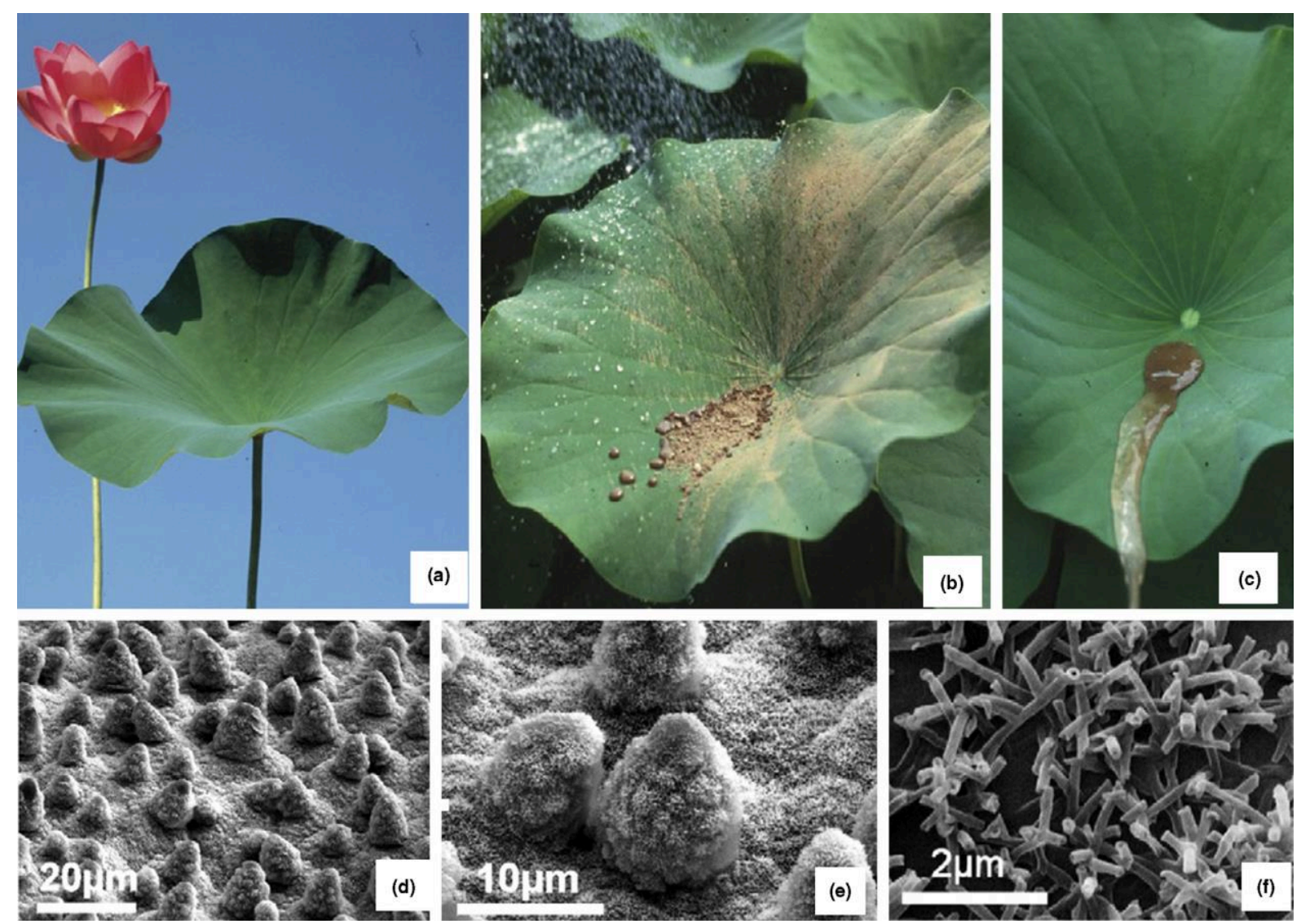

Figure 7: Images of a superhydrophobic lotus leaves (Nelumbo nucifera) with self-cleaning properties at different magnifications [107] 

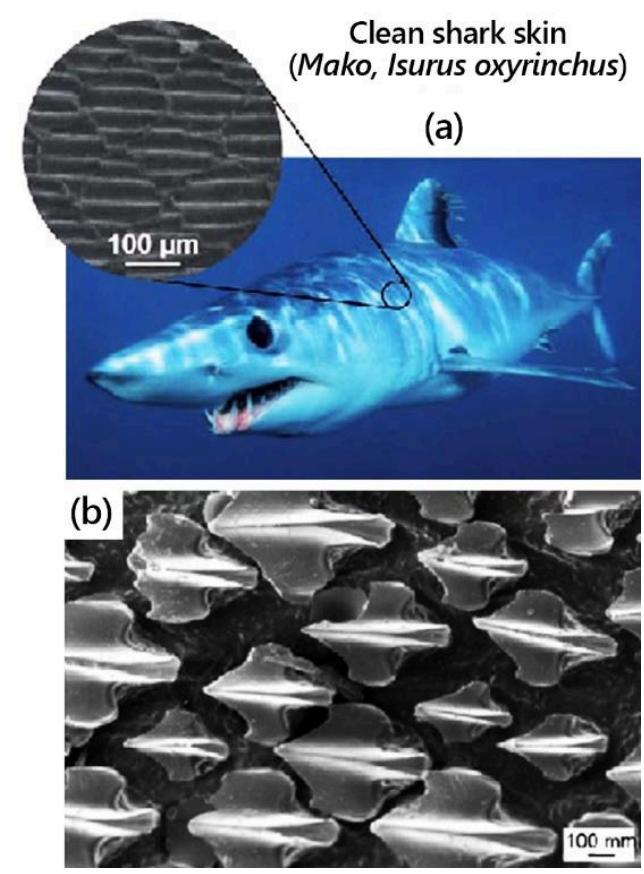

Figure 8: ( $a$ and b) Images at different magnifications of underwater shark skin showing characteristic surface geometry for self-cleaning behaviour [101].
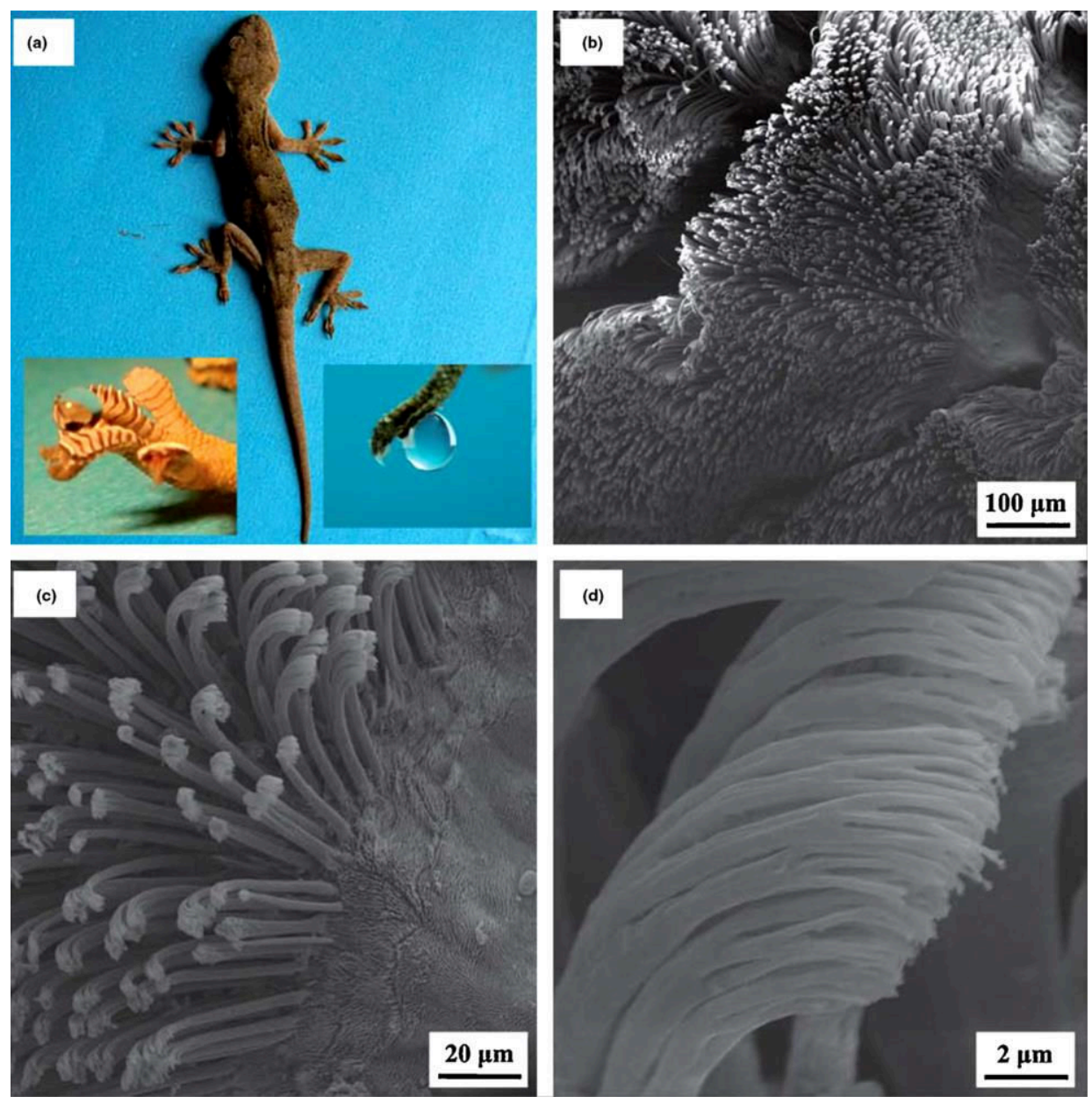

Figure 9: Images of superhydrophobic gecko foot with high adhesion at different magnifications, able to walk on vertical surfaces. [113] 

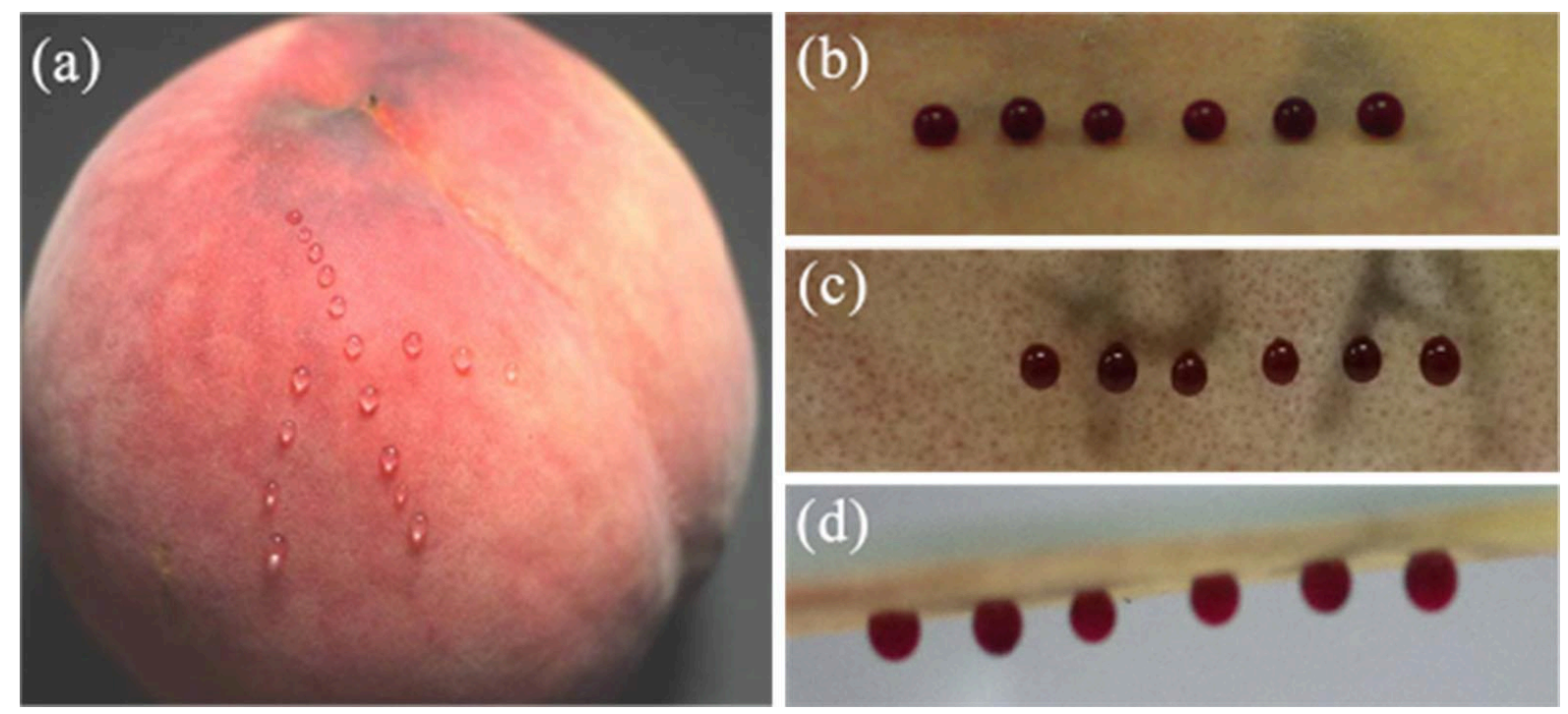

Figure 10: a) Digital photographs of a fresh peach with water droplets on the surface. Photographs of red ink droplets (10 $\mu \mathrm{L}$ ) on the surface of peach skin peeled off from a Pinggu peach with different tilt angles b) $0^{\circ}$, c) $90^{\circ}$, d) $180^{\circ}$ [117]

Using these and many others as inspiration, researchers have artificially developed and tested various reentrant geometrical features which show this liquid repellent behaviour. Common ones include electrospun fibre structure [118-121], T-structures [122-124], mushroom structure [123,125], Inverse trapezoidal structure $[8,126]$, sphere and microsphere structure [122] among many others.

The guiding principal behind these structures is the reentrant geometry which supports liquid droplets and keeps them away from the bottom surface. This role of reentrant geometry was evaluated by Cao et al. where they demonstrated that for superamphiphobicity to prevail $\theta_{\text {overhang }}<\theta_{\text {flat }}$ [127] as shown in Figure 11, which is a magnified view of area between 2 reentrant geometries. Wu et al. further explained as to how the structural geometry helps in achieving pressure balance in line with Equation 4 to facilitate superamphiphobic behaviour [128].

$$
P_{\text {max }}+\left(1-f_{s}\right) P_{\text {down }} \geq 0
$$

Where $P_{\max }$ is the upward pressure formulated due to the surface geometry and hence surface tensions $\gamma_{l v}$ and $\gamma_{s l}$, while $P_{\text {down }}$ is the combined pressure due to gravitational pull and capillary interaction (Laplace Pressure) of the liquid droplet. $f_{S}$ is the solid fraction under consideration which includes the reentrant geometries as defined in the Cassie-Baxter state previously. They concurred that if this equation is balanced, the surface will remain completely superamphiphobic.
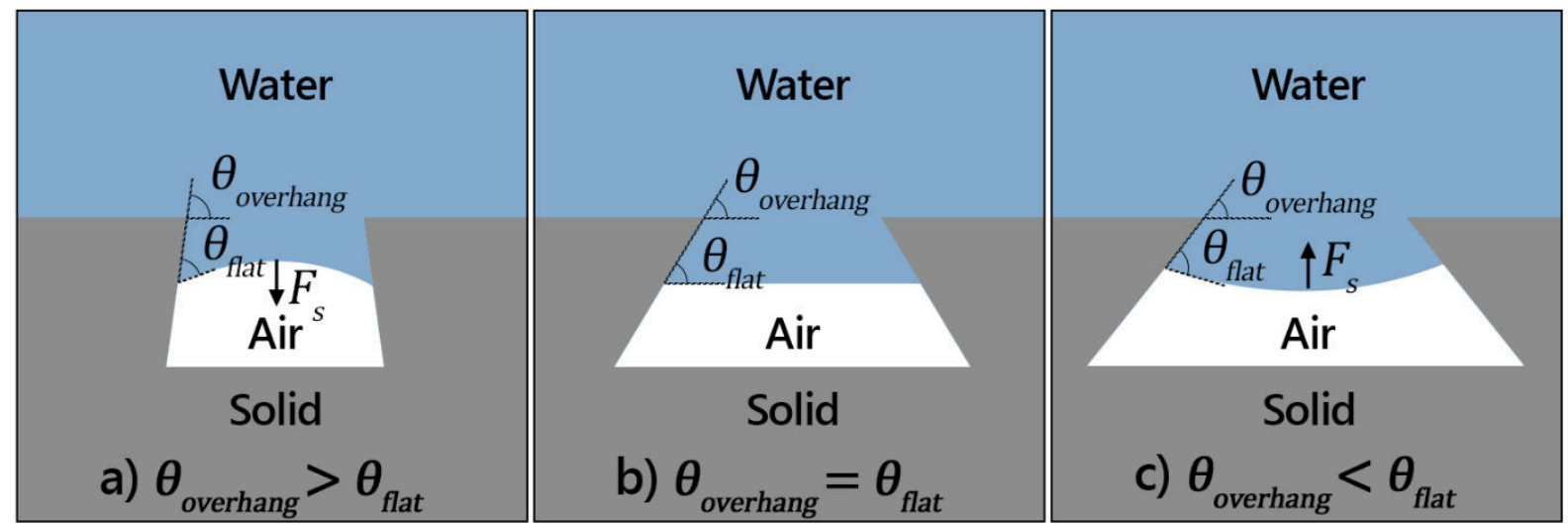

Figure 11: Three cross-sectional profiles of water in contact with a solid surface consisting of overhanging structures where $\boldsymbol{\theta}_{\text {overhang }}$ is the angle formed between the sidewalls and horizontal and $\boldsymbol{\theta}_{\text {flat }}$ is the intrinsic water contact angle. In a) 
The meniscus inside the indent is concave when viewed from the water side. The net force $\left(F_{s}\right)$ generated by the meniscus at the water-air interface causes water to enter the indent, completely wetting the solid. In b) The water-air interface is flat and stays at circular intersection of the indent and in c) the meniscus inside the indent is convex which enables the net force $\left(F_{S}\right)$ to point towards the outside of the indent, thereby preventing water from entering the indent. This formation of meniscus is guided by the geometry where the two angles $\boldsymbol{\theta}_{\text {overhang }}$ and $\boldsymbol{\theta}_{\text {flat }}$ are formed. (Image Recreated from Cao et al. [127] for High Resolution Printing)

A derived version of these reentrant profiles is the doubly reentrant structure $[16,41,129]$, so called because it may include more than one reentrant profile in a solid fraction. This geometrical configuration like the reentrant profile is also inspired from nature. These doubly reentrant structures may be created by overlapping one reentrant profile over another [130-132] as shown in Figure 12 or by introducing a much smaller scale structure over the original reentrant structure $[133,134]$ as shown in Figure 13.

a) Simple cavity

(SC)

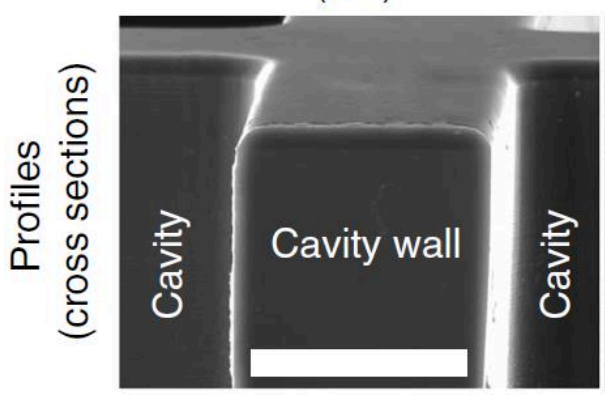

b) Reentrant cavity

$(\mathrm{RC})$

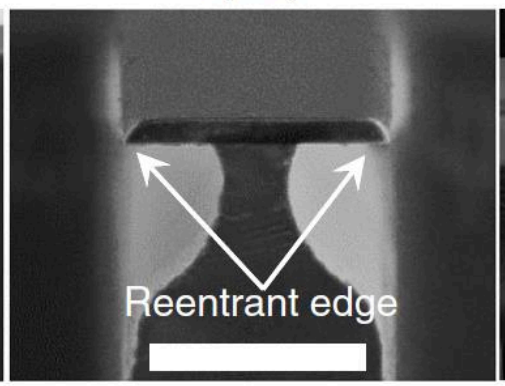

C) Doubly reentrant cavity (DRC)

Figure 12: SEM micrographs of three profile cross-sections showing a) Simple Cavity (SC), b) Reentrant Cavity (RC) and c) Doubly Renentrant Cavity (DRC) [130]

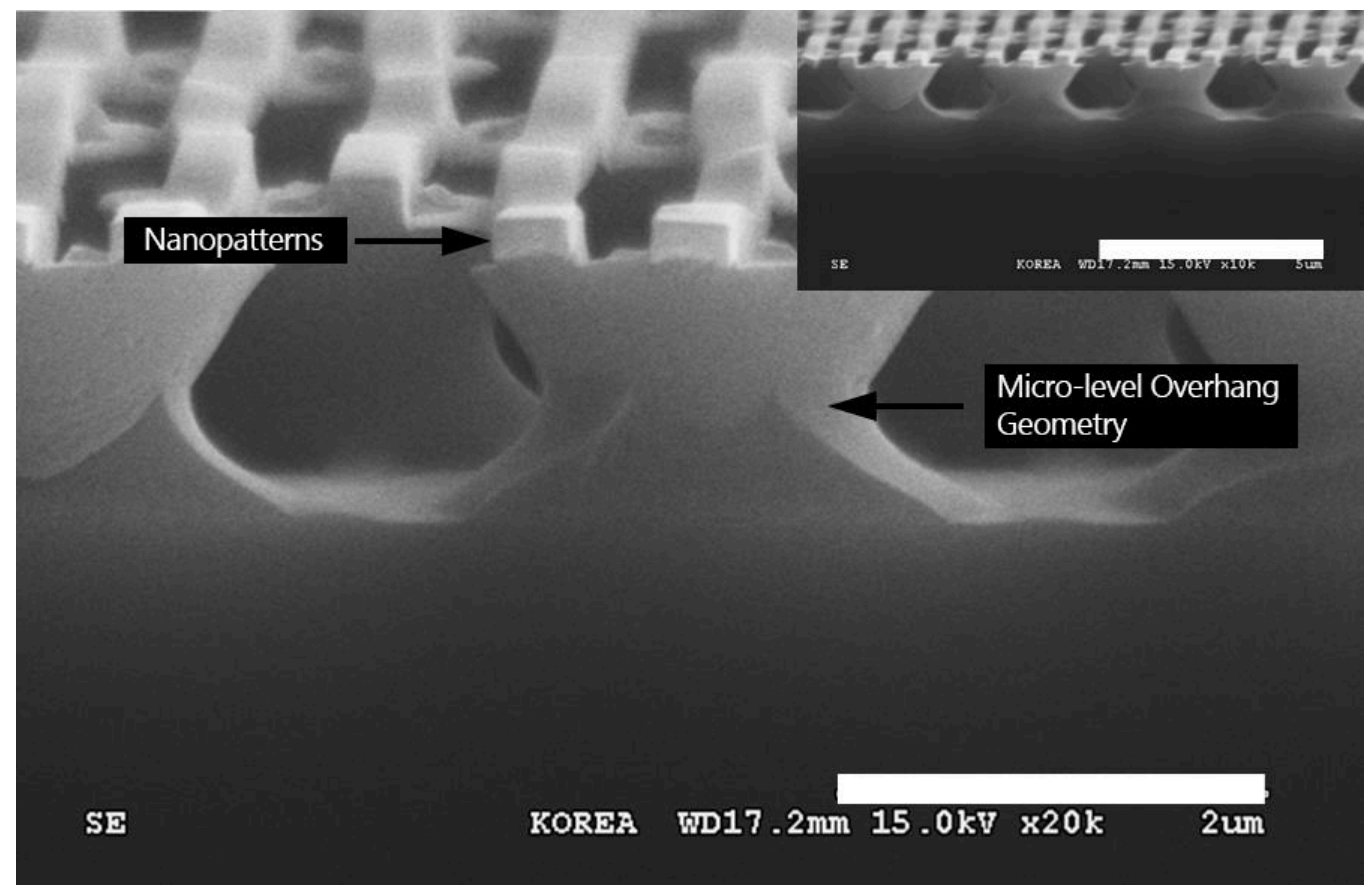

Figure 13: SEM micrograph showing a nanopatterns embedded on top of overhang structures. [133]

These doubly reentrant structures provide a more metastable Cassie-Baxter state by forming multiple $\theta_{\text {overhang }}<\theta_{\text {flat }}$ angles at various instances, essentially leading to a further increase in the energy barrier to failure [127]. They work by increasing the $P_{\max }$, thereby driving the liquid out of surface indents using the net force or pressure (developed at the meniscus of the water droplet inside the 
surface indent) to their favour, hence reducing the wetting potential of the surface and resulting in Low CAH as well as multi-level surface roughness [135].

This goes on to show that physical modification plays a vital role in altering the wetting characteristics of the surface without any dependency on the properties of the base material. However, to ensure this behaviour prevails, a key concern is to make these reentrant and doubly reentrant geometries more durable and reusable which is where selection of materials and manufacturing processes plays its part. This is because that while the naturally occurring surfaces can undergo repair and clean themselves through physical movement of the surface as in the case of muscle movement [136], the same is not easy to achieve artificially. A closer look at this problem suggests that Layer-by-Layer (LbL) deposition [137] and Autonomic / Non-Autonomic approaches [138] of self-healing surfaces can come close to the overall concept of surface regeneration after possible damage or degradation and additive manufacturing techniques provide a way forward in this direction.

\section{3D Printing of Reentrant Geometry}

Fabrication of geometrical features which can support amphiphobic or superamphiphobic interaction using additive manufacturing techniques is a forthcoming area of research in polymers. While Guo et al. and $\mathrm{Ai}$ et al. have adequately summarized most fabrication methodologies and challenges pertaining to creation of superamphiphobic surface modification on polymers $[40,139]$, this important method remains missing from their review.

Jafari et al. and Yan et al. in a first have addressed this area by reviewing some techniques that have been developed in recent years to achieve superamphiphobicity (including its subsets superhydrophobicity and superoleophobicity) in polymers using additive manufacturing techniques $[140,141]$. Additive manufacturing techniques follow a layer-by-layer building approach which means that even the most complex of reentrant geometries can be easily fabricated $[51,103]$. The challenge however remains that protrusions of micro- and nano- scale may not be easy to achieve with all additive manufacturing processes due to limitations in the process itself $[47,141]$. In the case where this limitation no longer exists as in the case of Two Photon Polymerization (2PP) [142] and Immersed Surface Accumulation (ISA) [51] techniques, the choice of available materials that can be used with them is severely limited and the fabrication setup extremely complicated.

The most commonly used additive manufacturing process is therefore Fused-Deposition Modelling (FDM), an extrusion based technique which falls under the broader heading of Liquid-based techniques for Additive manufacturing defined by Kruth et al $[47,143,144]$. A similar technique that is used along with FDM and is based on extrusion mechanism is Direct Ink Writing (DIW) [141] or Pressure Assisted Micro-syringe (PAM) [145], which is used with polymers in viscous form. It is important to mention here that both processes follow the same extrusion mechanism and have the most elaborate list of cross-platform generic materials that can be used with them. A major advantage thus of these processes is that if the printing unit allows for adjusting the printing parameters, any material that melts and flows within the working temperature range of the printing unit can be readily used [146]. This is not the case for other additive manufacturing processes like Stereolithography (SLA) which makes use of proprietary resins and hence is highly machine specific [147]. The complete list of materials (to the best of authors' current knowledge) that can be used with these extrusion-based processes is provided in Table 2. As can be inferred from this list, most of these materials are of high commercial importance. 
Table 2: List of Materials with their specific natural wetting state(s) due to intrinsic functional groups

\begin{tabular}{|c|c|c|c|}
\hline S/No. & Material Type & $\begin{array}{c}\text { Naturally Amphiphobic } \\
\text { (Yes/No/Hydrophobic/Oleophobic) }\end{array}$ & Reference(s) \\
\hline 1 & $\begin{array}{l}\text { Acrylonitrile Butadiene Styrene } \\
\text { (ABS) }\end{array}$ & Hydrophobic & [148] \\
\hline 2 & Poly Lactic Acid (PLA) & Hydrophobic & [149] \\
\hline 3 & PolyEthylene Terephthalate (PET) & No & {$[150,151]$} \\
\hline 4 & Nylon & No & [152] \\
\hline 5 & Polyvinyl Alcohol (PVA) & No & [153] \\
\hline 6 & Sandstone (PLA + Ceramic) & No & [154] \\
\hline 7 & Wood & Hydrophobic & [155] \\
\hline 8 & Metal (PLA with Metal Powder) & No & [154] \\
\hline 9 & High Impact Polystyrene (HIPS) & Yes & {$[154,156]$} \\
\hline 10 & Magnetic (PLA with Iron Fillings) & No & [154] \\
\hline 11 & Conductive (PLA with Carbon) & No & [154] \\
\hline 12 & Carbon Fiber (PLA with Carbon) & No & [154] \\
\hline 13 & $\begin{array}{l}\text { Flexible Thermoplastic Elastomers } \\
\text { (TPE) }\end{array}$ & Yes & [157] \\
\hline 14 & Polycarbonate (PC) & No & [158] \\
\hline 15 & Biodegradable (bioFila) & No & [154] \\
\hline 16 & Wax & Yes & [141] \\
\hline 17 & Acrylonitrile Styrene Acrylate (ASA) & No & [159] \\
\hline 18 & Polypropylene (PP) & Hydrophobic & [160] \\
\hline 19 & Acetal (POM) & Hydrophobic & [161] \\
\hline 20 & Polymethyl Methacrylate (PMMA) & Hydrophobic & [162] \\
\hline 21 & Polyvinylchloride (PVC) & No & [163] \\
\hline 22 & $\begin{array}{l}\text { PDMS } \\
\text { (Used in Combination with another } \\
\text { Elastomer) }\end{array}$ & Hydrophobic & {$[31,145]$} \\
\hline 23 & $\begin{array}{l}\text { Ethylcellulose (EC) } \\
\text { (Used with Plasticizer) }\end{array}$ & Hydrophobic & [145] \\
\hline 24 & Hydroxypropyl Cellulose (HPC) & No & {$[145,164]$} \\
\hline 25 & $\begin{array}{l}\text { Hydroxypropyl Methylcellulose } \\
\text { (HPMC) }\end{array}$ & No & [145] \\
\hline 26 & Polycaprolactone (PCL) & Yes & [29] \\
\hline 27 & Polyvinylpyrrolidone (PVP) & $\begin{array}{c}\text { Both Hydrophobic and Hydrophilic } \\
\text { Functional Groups Exist/ } \\
\text { Oleophobic }\end{array}$ & [165] \\
\hline 28 & Poly(Ethylene Glycol) (PEG) & No & [145] \\
\hline 29 & $\begin{array}{l}\text { Polyethylene Terephthalate Glycol } \\
\text { (PETG) }\end{array}$ & Hydrophobic & [166] \\
\hline 30 & $\begin{array}{l}\text { Polyethylene coTrimethylene } \\
\text { Terephthalate (PETT) }\end{array}$ & Hydrophobic & [166] \\
\hline
\end{tabular}

In any additive manufacturing process, the printing function itself (in this case the motion of extruder and material deposition rate) are machine controlled [167]. However, despite this automation the material deposition method especially in extrusion-based processes brings with it a natural process limitation in that the minimum feature size depends on the diameter of the final orifice and flowability of the material that has to pass through it [168] while maintaining a smooth print acceleration [166]. Furthermore, the layer-by-layer deposition leads to the formation of a natural surface geometry (referred to as the staircase or ladder effect) at the termination point of which layer, which when piled up exhibits its own surface roughness and wetting behaviour [169]. Moreover, an understanding of 
the printing process itself enables selective tinkering which can provide benefit in creation of superamphiphobic or its subset superhydrophobic and superoleophobic repellent states.

\subsection{Direct Ink Writing (DIW)}

In DIW based extrusion setup, an example of this can be seen in the work of Barahman et al who used a 27 gauge ( $210 \mu \mathrm{m}$ i.d.) tapered dispensing syringe mounted on a robotic arm [170]. By using the natural dispensing mechanism of the syringe to their advantage, they were able to fabricate ratchetlike asymmetric pyramid posts of poly(dimethylsiloxane) (PDMS) with slopes ranging from $0^{\circ}$ to $50^{\circ}$ to create a heterogenous superhydrophobic surface as shown in Figure 14. Due to natural adhesion in the polymer, the pyramid tip terminates at a specific angle at the time of disengagement which was used to create this unique ratchetlike geometry. The geometry provided favourable advantage to support directional rolling off of water droplets.
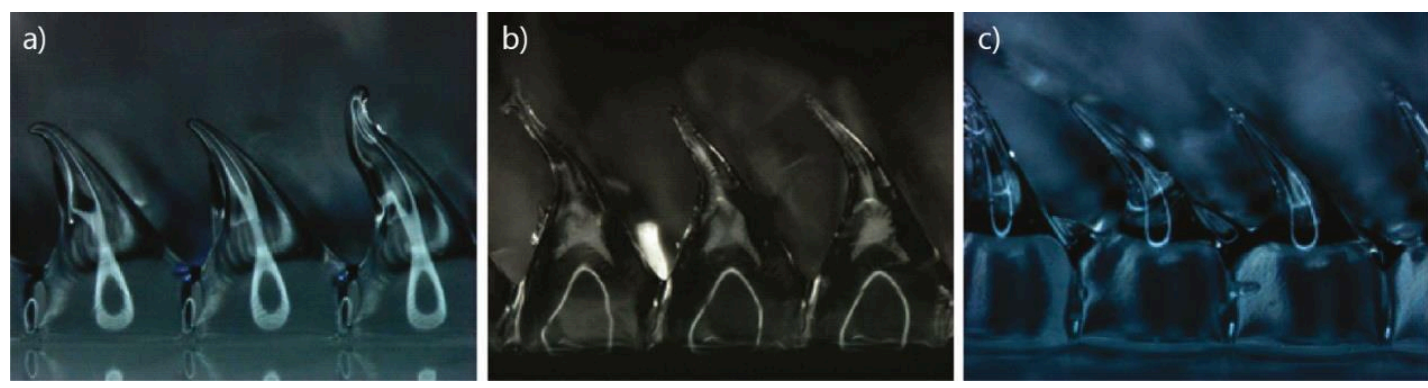

Figure 14: Optical microscopy images of asymmetric pyramid shaped PDMS created by selective disengagement at different angles where a) $35 \pm 1^{\circ}$ b) $44 \pm 5^{\circ}$ and c) $50 \pm 1^{\circ}$ [170]

Similarly, He et al. also fabricated an anisotropic porous PDMS film by using a DIW based extrusion setup. They printed lines in parallel and perpendicular directions to create a mesh like porous film volume and developed multiple samples of the same by varying the printing speed and filament spacing. It was observed that the printing speed in turn effects the filament diameter since more material is deposited at lower speeds. The effect of these 03 factors was demonstrated in terms of changing wettability behaviour due to the formation of various geometrical structures as shown in Figure 15 and Figure 16 where the maximum CA of $155^{\circ}$ were favourably achieved through their optimization [171]. 

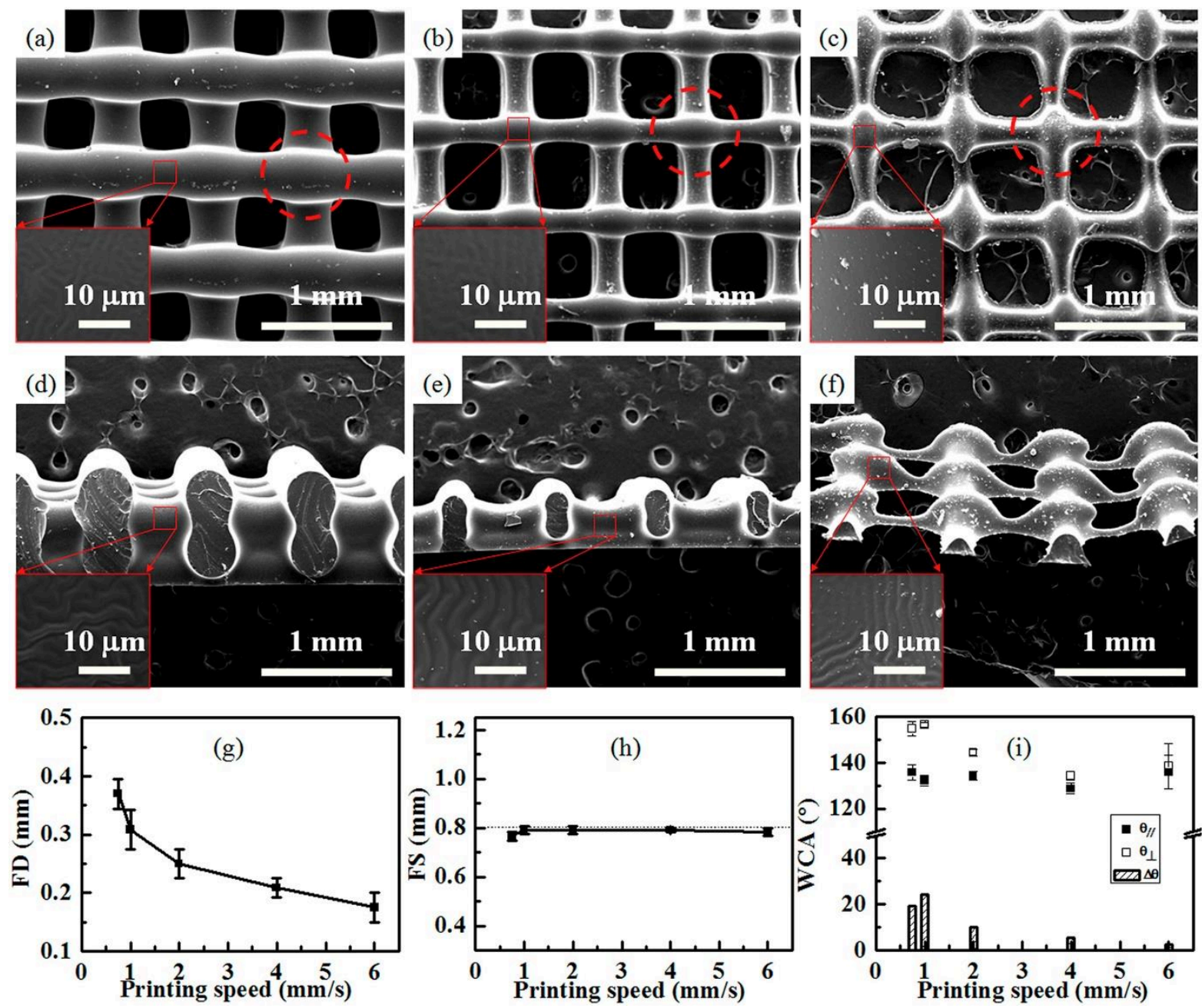

Figure 15: SEM images of surface $(a \sim c)$ and cross-section ( $d \sim f)$ morphology for samples printed at different printing speeds of 0.75 ( $a$ and d), 2.00 (b and e), and $6.00 \mathrm{~mm} / \mathrm{s}$ (c and f). The insets show the higher magnification images. The edges of cross-points between filaments from neighboured printing layers are shown in red dash circles in ( $d \sim f$ ). Filament Diameter (g) and Filament Spacing (h) change with increasing printing speed from 0.75 to $6.00 \mathrm{~mm} / \mathrm{s}$. The dash line in (h) indicates the Filament Spacing value which is set by computer program. (i) The averaged Water Contact Angles in perpendicular and parallel directions and their $\Delta \theta$ change with various printing speed. [171] 

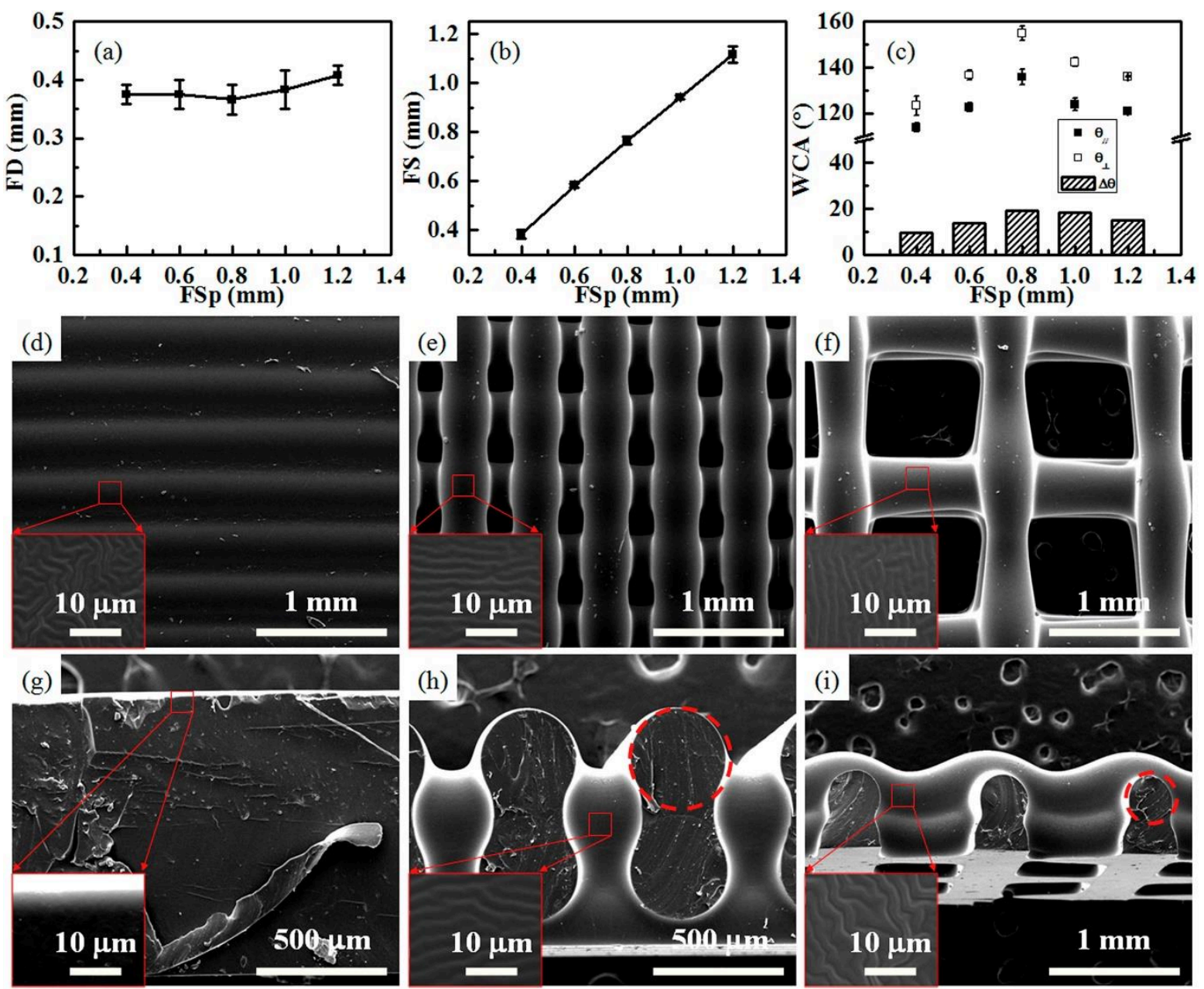

Figure 16: Filament Diameter (a) and Filament Spacing (b) change with increasing FSp from 0.40 to $1.20 \mathrm{~mm}$. The Water Contact Angles in perpendicular and parallel directions and their $\Delta \theta$ change with various Filament Spacings (c). SEM images of surface $(d \sim f)$ and cross-section $(g \sim i)$ morphology for samples with various Filament Spacing of $0.40(d$ and $g$ ), 0.60 (e and $\mathrm{h}$ ), and $1.20 \mathrm{~mm}$ (f and i). [171]

Another facile method of this type was reported by Lv et al. for creating superhydrophobicity with the use of polydimethylsiloxane (PDMS) ink whose flowability (rheological behaviour) was suitably tailored for 3D printing with the addition of hydrophobic silica nanoparticles [172]. Here hydrophobic silica not only enhanced the hydrophobic effect but in turn also provided the mechanical support to the structure to prevent it from premature collapsing. A membrane structure was developed with an average pore size of $0.37 \mathrm{~mm}$. The membrane showed suitable results as an oil-water separation barrier with a high efficiency of $99 \%$. Similar to this, Li et al. used printing ink consisting of a mixture of cellulose acetate (CA), poly (viny1 alcohol) (PVA), and silica nano-particles $\left(\mathrm{SiO}_{2}\right)$ to fabricate a highly superoleophobic membrane for oil-water separation with oil contact angles reaching up to $159^{\circ}$ underwater [173]. These methods show the ease with which a complex geometry such as that of a membrane can easily be developed in a single-step printing process without any additional modification.

Building up on it, Shin et al. used the DIW technique to create negative sponge templates. These templates were later filled with PDMS and then suitably dissolved to create another oil-water separation barrier especially for use as a sponge to clean marine oil spills [174]. This created a highly superhydrophobic but oleophilic structure with a 3.7 times greater efficiency as compared to the traditional PDMS sponge. Where the sponge structure absorbed and exuded as desired, it's reusability over long-term was not gauged which might limit its use, since PDMS is non-biodegradable in nature [175]. 


\subsection{Fused Deposition Modelling (FDM)}

Where DIW based extrusion setups have shown credible results, FDM based extrusion techniques are also not lagging behind. In recent years extrusion based FDM technique has been applied to modify a surface wettability behaviour. Two approaches using FDM technique were developed by Kang et al. $[176,177]$ using PLA based moulds for casting PDMS. In their first approach, a simple plate design was printed at increasing angles between $0^{\circ}$ to $90^{\circ}$ at $10^{\circ}$ increment while keeping a fixed layer height. The changing angle resulted in variable surface profiles formed at the termination point of the layer deposition process as shown in Figure 17 and Figure 18. CAs were measured on the surfaces produced and it was seen that while increasing the printing angle leads to a higher CA with water, $70^{\circ}$ angle provided the best result in terms of water rolling off or a low CAH.

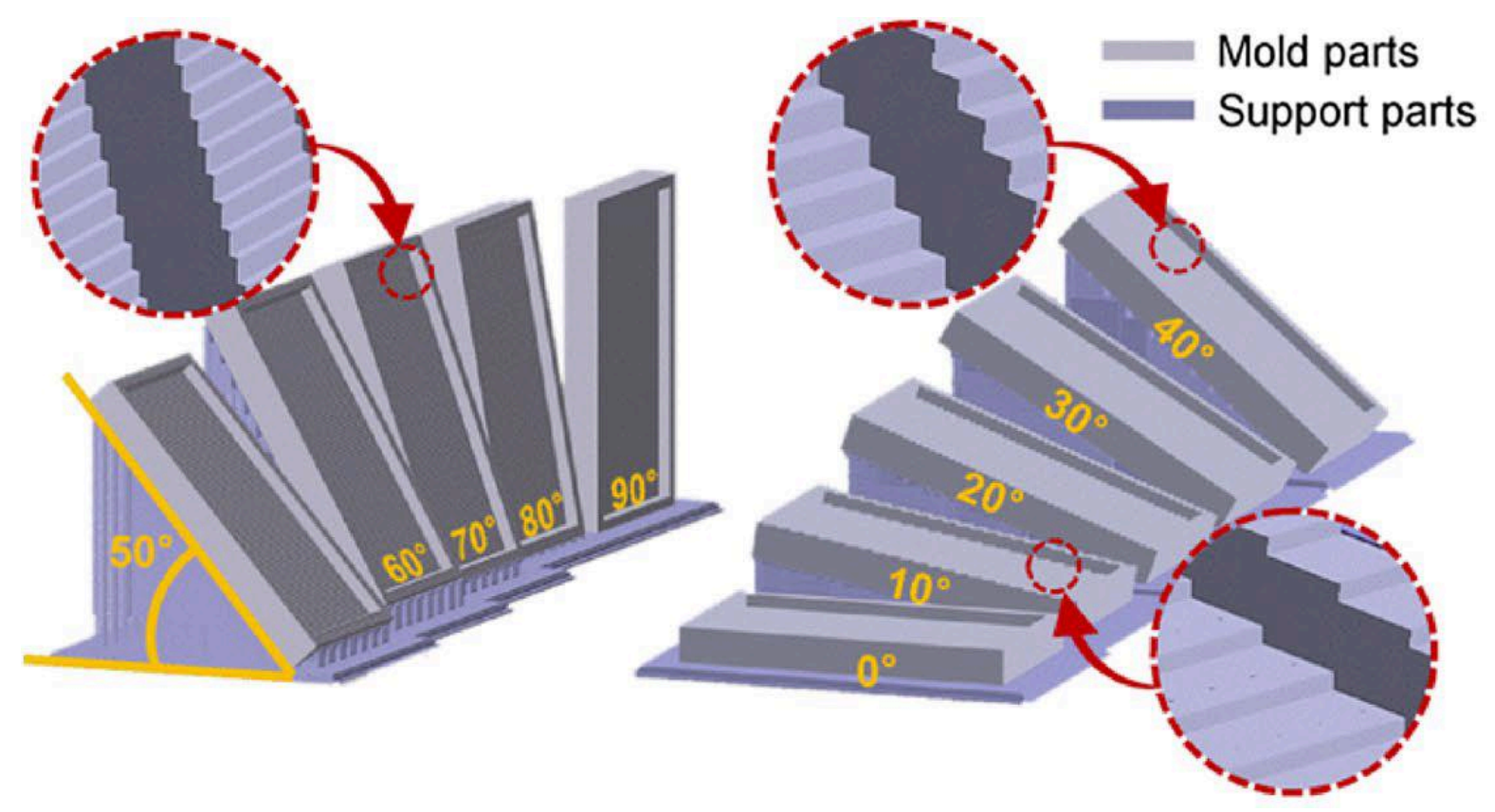

Figure 17: CAD images of main 3D mould parts on support parts with respect to various printing angles [176].

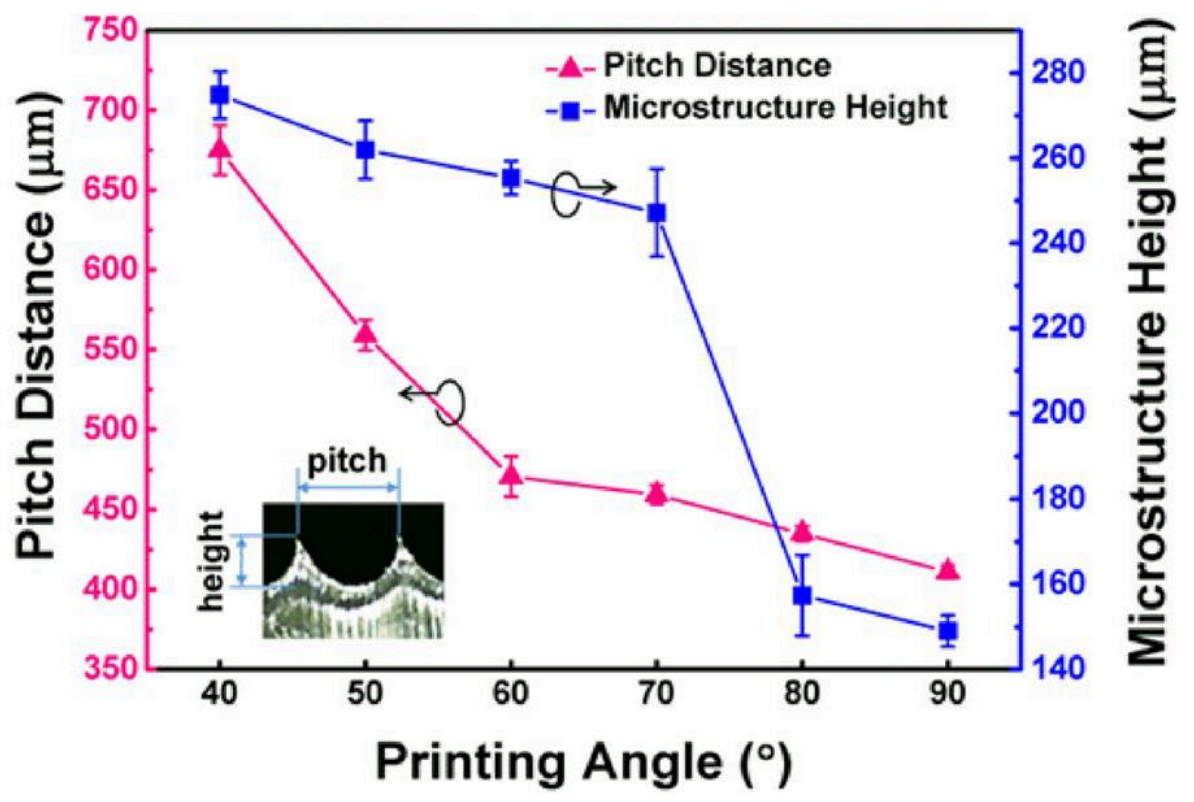

Figure 18: Graph show variation of Pitch Distance and Microstructure Height as a function of printing angle from $40^{\circ}$ to $90^{\circ}[176]$.

In the second approach, they 3D printed PLA based moulds consisting of inverted pyramid shaped profiles. This time, the layer height was made variable by changing the printing parameters while the 
angle of inclination of the pyramid was set at a fixed angle. The roughest surface which was about 300 $\mu \mathrm{m}$ in height attributed the highest CA of $143^{\circ}$.

Furthermore, Milionis et al. [178] and Lee et al. [179] demonstrated the use of a low cost FDM technique to realize superhydrophobicity on relatively non-hydrophobic polymers. Milionis et al. used Acrylonitrile Butadiene Styrene (ABS) while Lee et al. used Polylactic Acid (PLA), both of which are widely used in 3D printing.

Milionis et al. printed cube shaped heat exchanger designs using ABS and modified their surfaces using dip-coating technique. The samples were pre-prepped using two different approaches where one batch of samples was sputtered with Gold-Palladium particles while the other batch was coated with superhydrophilic rubber coating to act as primer. Both batches of samples were then coated with fluoride based superhydrophobic coating using dip-coating. CAs of $120^{\circ}$ and $154.7^{\circ}$ were achieved using the first and second approach respectively. The surface geometry of the printed part played little role in determining the superhydrophobic surface properties of the material and the chemical modification can be attributed as the primary reason for this effect.

Lee et al. printed a plate design keeping lines as the infill pattern. Two types of line patterns created due to Layer-by-Layer deposition and Tool path (Infill pattern) were then selectively modified by dissolving the top surface in methyl ethyl ketone (MEK) and coating them simultaneously with hydrophobic silica nanoparticles in a single dip coating process followed by drying. CAs of up to $150^{\circ}$ were achieved. The technique was also repeated on step and grid patterns with highly favourable results.

Another low-cost 3D Printing method was employed by Cook et al. to create anisotropic wettability on polymer substrate [180]. Line patterns with channels in between were designed and printed using ABS followed by PLA varying between $250 \mu \mathrm{m}$ to $1 \mathrm{~mm}$ in width and tested for wetting characteristics by measurement of Contact Angle and Tilt Angle in Parallel and Perpendicular direction using water. Samples were then modified in 03 different ways. First set of samples were modified chemically, while the second set of samples was modified by a physical treatment. For the third set a combination of the two was employed. They were able to demonstrate a significant difference in rolling off the water droplet in parallel and perpendicular direction, where the parallel direction facilitated water to flow (hydrophobic) the perpendicular direction made the drop sticky (hydrophilic). The employed treatments greatly altered the wettability behaviour where the physical modification rendered the sample hydrophilic in most cases. While this study provides a way through for using FDM printers for developing hydrophobic polymeric surfaces, it neglects the natural reentrant profile that is created by Layer-by-Layer deposition during the 3D printing procedure. It further also does not specify the effect of pattern height or channel depth, which is an important parameter in this investigation.

Table 3 provides a summary of the findings in this review. As can be deduced from the table, most researchers when using either DIW or FDM based approaches have relied on materials that already exhibit repellency against a liquid. Whereas, materials like Polyvinylchloride (PVC) and Polyethylene Terephthalate Glycol (PETG) which are the most abundantly used polymers for handling liquids have never been worked upon. The efficacy of reentrant geometrical features on their surfaces and the parameters that govern the printing process itself in these extrusion-based techniques is therefore a novel area of research. 
Table 3: Summary of Extrusion-Based Methods used to develop Amphiphobic Surface Modification in Polymers

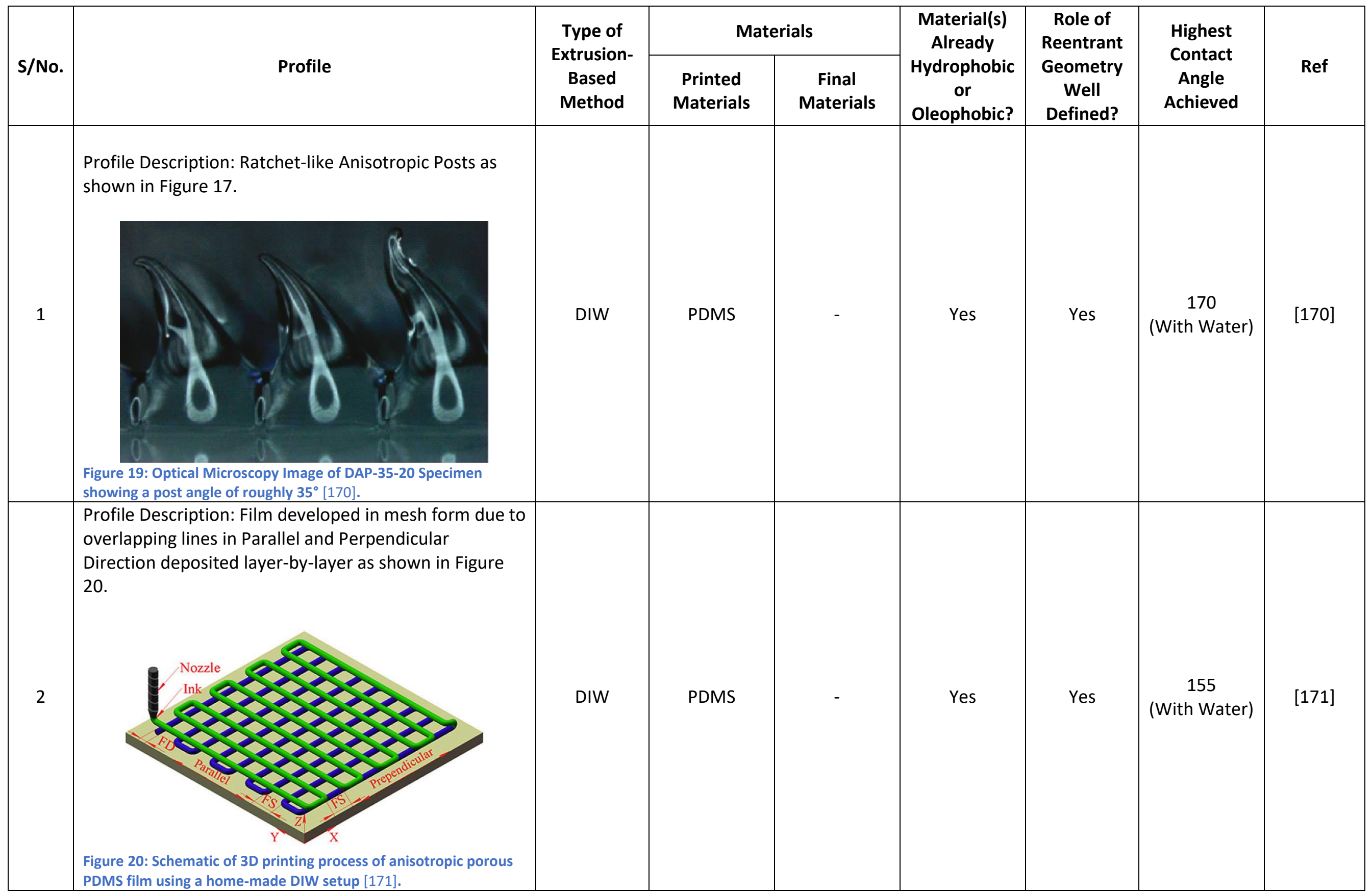




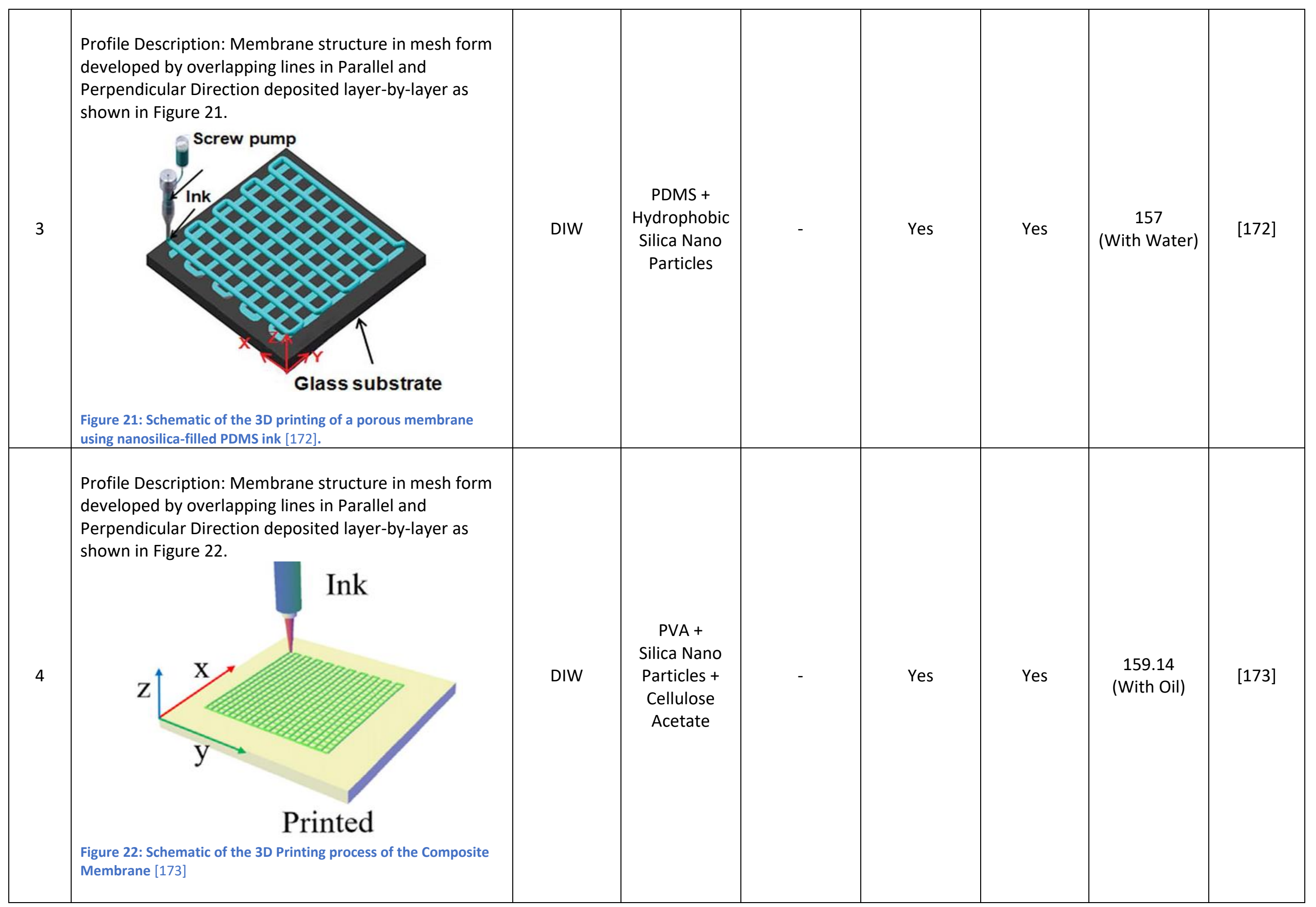




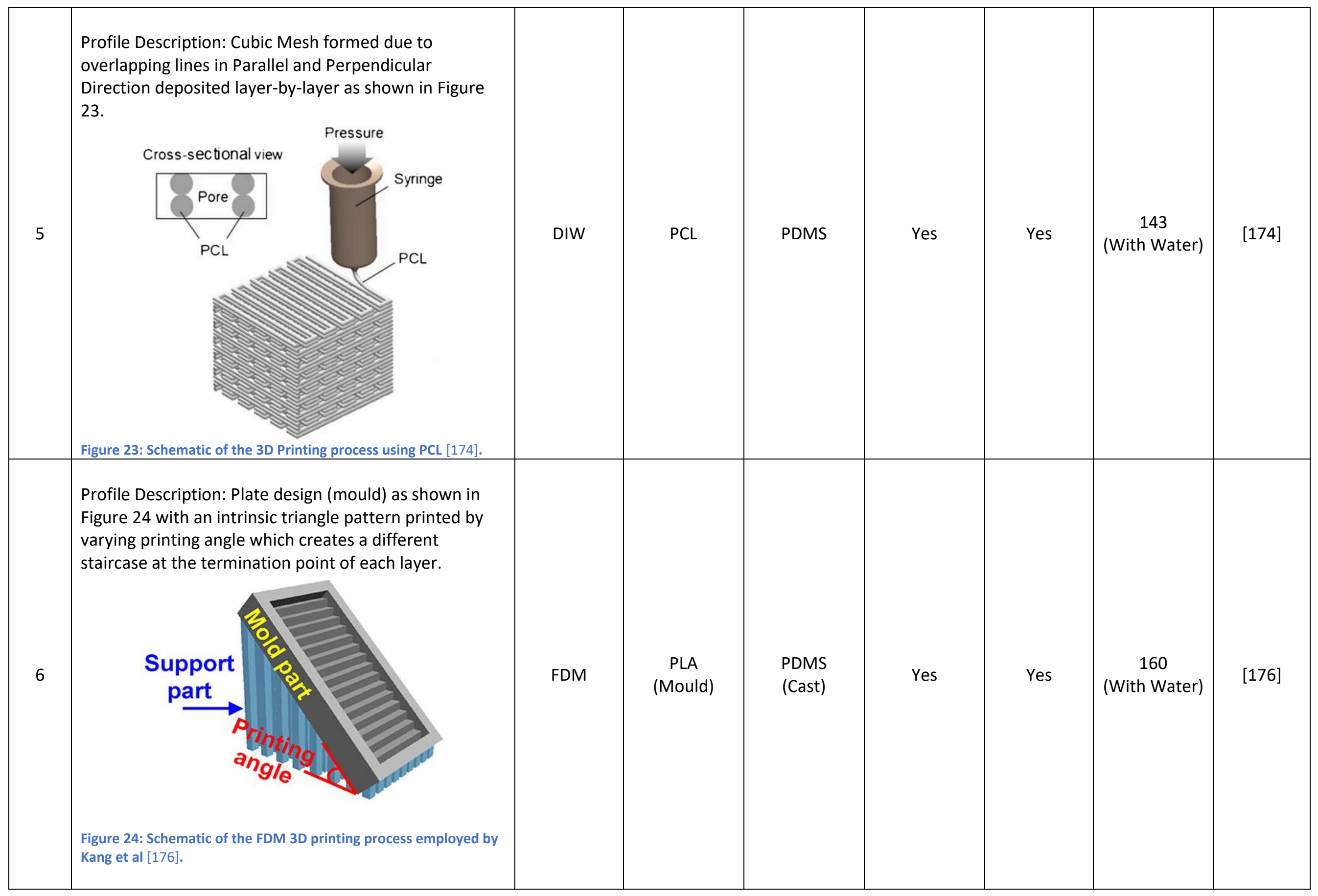




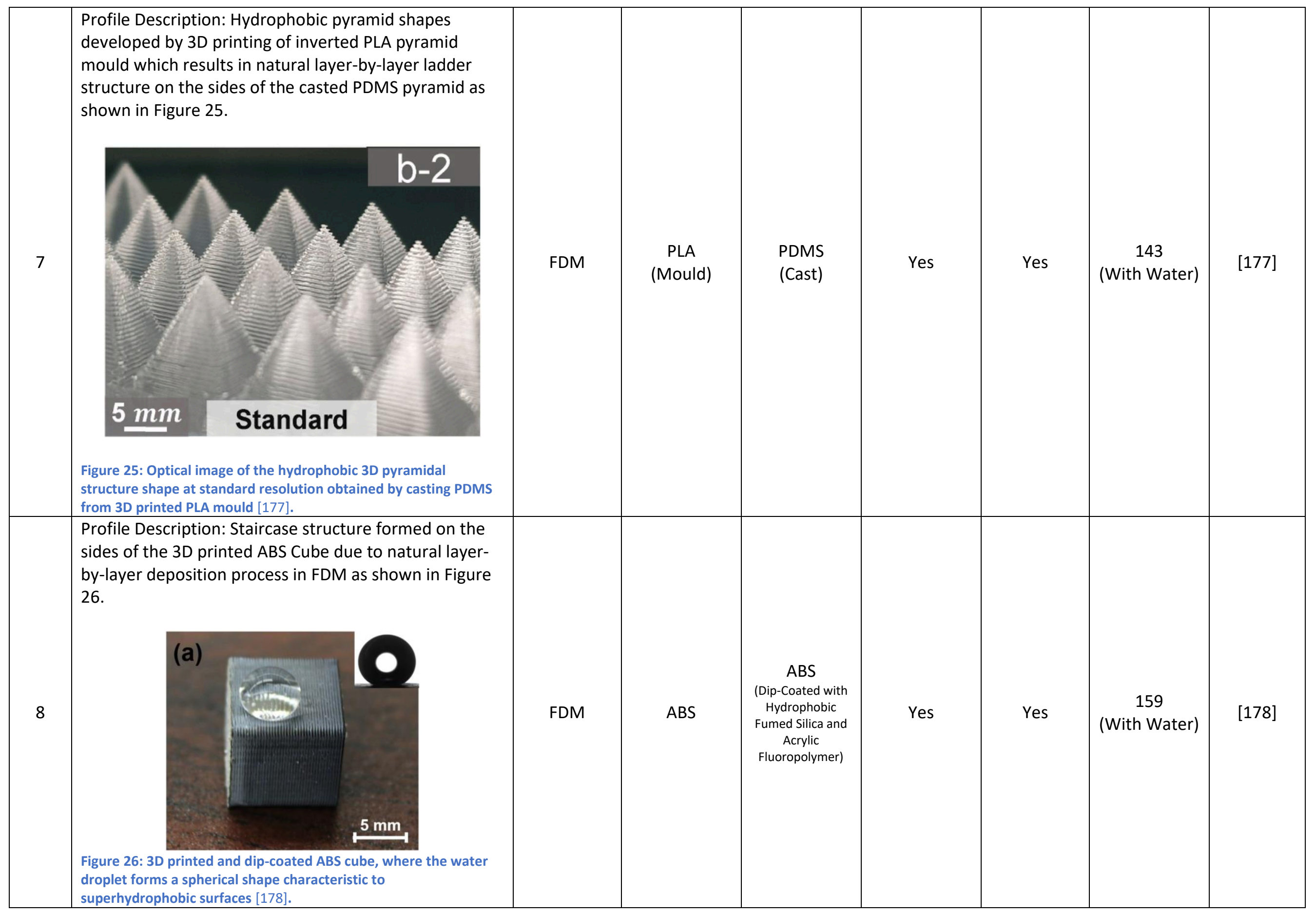




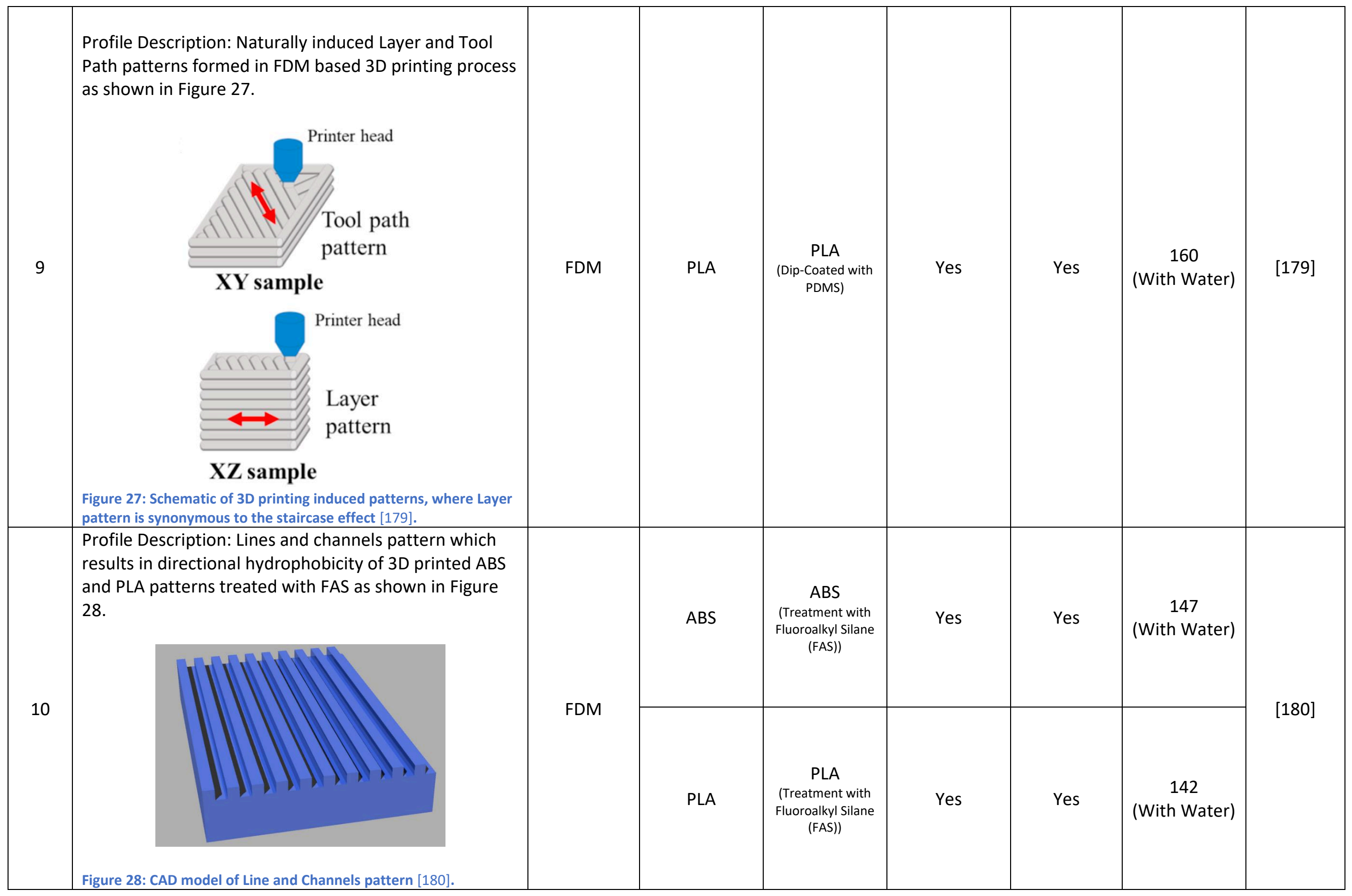




\section{Conclusion:}

This structured review presents a new forthcoming use of additive manufacturing techniques for inducing superamphiphobicity (including superhydrophobic and superoleophobic) in surfaces. It goes on to show how surface wettability can be suitably designed in the system by additive manufacturing of reentrant surface structures that limit dependency on the base material and are responsible for a smooth transition towards achieving a heterogenous wetting state (Cassie-Baxter).

The most established additive manufacturing techniques are extrusion based Fused Deposition Modelling (FDM) and Direct Ink Writing (DIW) or Pressure Assisted Micro-syringe (PAM) processes which have an extension range of freely available, cross-platform compatible materials of high commercial importance.

While reviewing the articles in this area (See Table 3), it is clearly observed that researchers have previously used materials which already exhibit repellency against a liquid which overshadowed the role of surface reentrant geometries in their design. Furthermore, in doing so they have neglected the full range of materials (See Table 2) especially those of high commercial importance like PVC and PETG whose surface wettability states can be redefined using reentrant structures. This means that an established route for design of reentrant geometries using the layer-by-layer deposition approach of these extrusion-based techniques is not available. To establish this route, one requires a clear understanding of process specific characteristics like the orifice diameter of the nozzle and material flowability including the movement of the extruder (print acceleration) which would determine as to how these parameters can be selectively exploited for generation of a complex set of reentrant features for superamphiphobic applications.

Reentrant geometry holds immense importance in modification of wettability behaviour where a pure amphiphilic surface can be rendered amphiphobic (or its derived state) with the formation of a correct reentrant geometry. Through this review it has been identified that with a background knowledge of parameters defining the reentrant geometry, an endless array of geometrical features can be easily designed in a CAD software and 3D printed to control surface wettability. Where extrusion-based additive manufacturing processes due to their simplicity and wide-range of material choices need to be explored further.

\section{References}

[1] K. Shinoda, H. Kunieda, T. Arai, H. Saijo, Principles of attaining very large solubilization (microemulsion): inclusive understanding of the solubilization of oil and water in aqueous and hydrocarbon media, J. Phys. Chem. 88 (1984) 5126-5129.

https://doi.org/10.1021/j150665a065.

[2] A. Nakajima, A. Fujishima, K. Hashimoto, T. Watanabe, Preparation of transparent superhydrophobic boehmite and silica films by sublimation of aluminum acetylacetonate, Adv. Mater. 11 (1999) 1365-1368. https://doi.org/10.1002/(SICI)15214095(199911)11:16<1365::AID-ADMA1365>3.0.CO;2-F.

[3] K. Tadanaga, J. Morinaga, A. Matsuda, T. Minami, Superhydrophobic - Superhydrophilic micropatterning on flowerlike alumina coating film by the sol - Gel method, Chem. Mater. 12 (2000) 590-592. https://doi.org/10.1021/cm990643h. 
[4] X.B. Wang, Y.Q. Liu, D.B. Zhu, Honeycomb-like alignments of carbon nanotubes synthesized by pyrolysis of a metal phthalocyanine, Appl. Phys. A Mater. Sci. Process. 71 (2000) 347-348. https://doi.org/10.1007/s003390000604.

[5] L. Jiang, R. Wang, B. Yang, T.J. Li, D.A. Tryk, A. Fujishima, K. Hashimoto, D. B. Zhu, Binary cooperative complementary nanoscale interfacial materials, Pure Appl. Chem. 72 (2000) 7381. https://doi.org/10.1351/pac200072010073.

[6] D. Öner, T.J. McCarthy, Ultrahydrophobic surfaces. Effects of topography length scales on wettability, Langmuir. 16 (2000) 7777-7782. https://doi.org/10.1021/la000598o.

[7] C.W. Extrand, Criteria for ultralyophobic surfaces, Langmuir. 20 (2004) 5013-5018. https://doi.org/10.1021/la036481s.

[8] M. Nosonovsky, B. Bhushan, Why re-entrant surface topography is needed for robust oleophobicity, Philos. Trans. R. Soc. A Math. Phys. Eng. Sci. 374 (2016).

https://doi.org/10.1098/rsta.2016.0185.

[9] H. Li, X. Wang, Y. Song, Y. Liu, Q. Li, L. Jiang, D. Zhu, Super-"amphiphobic" aligned carbon nanotube films, Angew. Chemie - Int. Ed. 40 (2001) 1743-1746. https://doi.org/10.1002/1521-3773(20010504)40:9<1743::AID-ANIE17430>3.0.CO;2-\#.

[10] A. Cavalli, F. Mugele, Superamphiphobic Surfaces, in: Droplet Wetting and Evaporation, Elsevier Inc., 2015: pp. 57-69. https://doi.org/10.1016/b978-0-12-800722-8.00005-9.

[11] B. Bhushan, Y.C. Jung, K. Koch, Micro-, nano- And hierarchical structures for superhydrophobicity, self-cleaning and low adhesion, Philos. Trans. R. Soc. A Math. Phys. Eng. Sci. 367 (2009) 1631-1672. https://doi.org/10.1098/rsta.2009.0014.

[12] K. Ellinas, A. Tserepi, E. Gogolides, Durable superhydrophobic and superamphiphobic polymeric surfaces and their applications: A review, Adv. Colloid Interface Sci. 250 (2017) 132-157. https://doi.org/10.1016/j.cis.2017.09.003.

[13] Z. Chu, S. Seeger, Superamphiphobic surfaces, Chem. Soc. Rev. 43 (2014) 2784-2798. https://doi.org/10.1039/c3cs60415b.

[14] T. Young, III. An essay on the cohesion of fluids, Philos. Trans. R. Soc. London. 95 (1805) 6587. https://doi.org/10.1098/rstl.1805.0005.

[15] D.M. Spori, T. Drobek, S. Zürcher, M. Ochsner, C. Sprecher, A. Mühlebach, N.D. Spencer, Beyond the lotus effect: Roughness influences on wetting over a wide surface-energy range, Langmuir. 24 (2008) 5411-5417. https://doi.org/10.1021/la800215r.

[16] J.R. Panter, Y. Gizaw, H. Kusumaatmaja, Multifaceted design optimization for superomniphobic surfaces, Sci. Adv. 5 (2019) 1-12. https://doi.org/10.1126/sciadv.aav7328.

[17] A. Tuteja, W. Choi, J.M. Mabry, G.H. McKinley, R.E. Cohen, Robust omniphobic surfaces, Proc. Natl. Acad. Sci. U. S. A. 105 (2008) 18200-18205. https://doi.org/10.1073/pnas.0804872105.

[18] Z. Wang, T. Wu, Modeling pressure stability and contact-angle hysteresis of superlyophobic surfaces based on local contact line, J. Phys. Chem. C. 119 (2015) 12916-12922. https://doi.org/10.1021/jp512930d.

[19] E. Bormashenko, Progress in understanding wetting transitions on rough surfaces, Adv. Colloid Interface Sci. 222 (2015) 92-103. https://doi.org/10.1016/j.cis.2014.02.009. 
[20] H. Liu, Y. Wang, J. Huang, Z. Chen, G. Chen, Y. Lai, Bioinspired Surfaces with Superamphiphobic Properties: Concepts, Synthesis, and Applications, Adv. Funct. Mater. 28 (2018) 1-27. https://doi.org/10.1002/adfm.201707415.

[21] C. Yu, S. Sasic, K. Liu, S. Salameh, R.H.A. Ras, J.R. van Ommen, Nature-Inspired self-cleaning surfaces: Mechanisms, modelling, and manufacturing, Chem. Eng. Res. Des. 155 (2020) 4865. https://doi.org/10.1016/j.cherd.2019.11.038.

[22] X. Yin, B. Yu, Antifouling Surfaces and Materials, Springer Berlin Heidelberg, Berlin, Heidelberg, 2015. https://doi.org/10.1007/978-3-662-45204-2.

[23] Y. Shen, X. Wu, J. Tao, C. Zhu, Y. Lai, Z. Chen, Icephobic materials: Fundamentals, performance evaluation, and applications, Prog. Mater. Sci. 103 (2019) 509-557. https://doi.org/10.1016/j.pmatsci.2019.03.004.

[24] M. Ran, W. Zheng, H. Wang, Fabrication of superhydrophobic surfaces for corrosion protection: a review, Mater. Sci. Technol. (United Kingdom). 35 (2019) 313-326. https://doi.org/10.1080/02670836.2018.1560985.

[25] M. Liravi, H. Pakzad, A. Moosavi, A. Nouri-Borujerdi, A comprehensive review on recent advances in superhydrophobic surfaces and their applications for drag reduction, Prog. Org. Coatings. 140 (2020) 105537. https://doi.org/10.1016/j.porgcoat.2019.105537.

[26] F. Veronesi, G. Boveri, M. Raimondo, Amphiphobic nanostructured coatings for industrial applications, Materials (Basel). 12 (2019). https://doi.org/10.3390/ma12050787.

[27] Z. Zhang, X. Guo, H. Tang, J. Ding, Y.-G. Zheng, S. Li, Unidirectional Self-Driving Liquid Droplet Transport on a Monolayer Graphene-Covered Textured Substrate, ACS Appl. Mater. Interfaces. 11 (2019) 28562-28570. https://doi.org/10.1021/acsami.9b09219.

[28] S. Huang, J. Song, Y. Lu, C. Lv, H. Zheng, X. Liu, Z. Jin, D. Zhao, C.J. Carmalt, I.P. Parkin, Powerfree water pump based on a superhydrophobic surface: Generation of a mushroom-like jet and anti-gravity long-distance transport, J. Mater. Chem. A. 4 (2016) 13771-13777. https://doi.org/10.1039/c6ta04908g.

[29] N. Narayanan, L. Kuang, M. Del Ponte, C. Chain, M. Deng, Design and fabrication of nanocomposites for musculoskeletal tissue regeneration, in: Nanocomposites Musculoskelet. Tissue Regen., Elsevier, 2016: pp. 3-29. https://doi.org/10.1016/B978-1-78242-452-9.000017.

[30] B.E. Obi, Overview of Applications of Polymeric Foams, Polym. Foam. Struct. (2018) 3-14. https://doi.org/10.1016/b978-1-4557-7755-6.00001-x.

[31] F. Wang, S. Lei, J. Ou, W. Li, Effect of PDMS on the waterproofing performance and corrosion resistance of cement mortar, Appl. Surf. Sci. 507 (2020). https://doi.org/10.1016/j.apsusc.2019.145016.

[32] X. Gong, S. He, Highly Durable Superhydrophobic Polydimethylsiloxane/Silica Nanocomposite Surfaces with Good Self-Cleaning Ability, ACS Omega. 5 (2020) 4100-4108. https://doi.org/10.1021/acsomega.9b03775.

[33] A.S. Sarkın, N. Ekren, Ş. Sağlam, A review of anti-reflection and self-cleaning coatings on photovoltaic panels, Sol. Energy. 199 (2020) 63-73. https://doi.org/10.1016/j.solener.2020.01.084. 
[34] T. "Leo" Liu, C.-J. "CJ" Kim, Turning a surface superrepellent even to completely wetting liquids, Science (80-. ). 346 (2014) 1096-1100. https://doi.org/10.1126/science.1254787.

[35] Y. Zuo, L. Zheng, C. Zhao, H. Liu, Micro-/Nanostructured Interface for Liquid Manipulation and Its Applications, Small. 16 (2020) 1-29. https://doi.org/10.1002/smll.201903849.

[36] M. Silvestrini, C. Brito, Wettability of Reentrant Surfaces: A Global Energy Approach, Langmuir. 33 (2017) 12535-12545. https://doi.org/10.1021/acs.langmuir.7b03230.

[37] E.S. Savoy, F.A. Escobedo, Simulation Study of Free-Energy Barriers in the Wetting Transition of an Oily Fluid on a Rough Surface with Reentrant Geometry, Langmuir. 28 (2012) 1608016090. https://doi.org/10.1021/la303407r.

[38] F.L. Palmieri, C.J. Wohl, Topographical modification of polymers and metals by laser ablation to create superhydrophobic surfaces, Laser Technol. Appl. Adhes. Relat. Areas. (2017) 3-68. https://doi.org/10.1002/9781119185031.ch1.

[39] J. Zhang, Z. Yao, P. Hao, Formation and evolution of air-water interfaces between hydrophilic structures in a microchannel, Microfluid. Nanofluidics. 21 (2017) 1-8. https://doi.org/10.1007/s10404-017-1968-6.

[40] J. Ai, Z. Guo, Biomimetic polymeric superamphiphobic surfaces: Their fabrication and applications, Chem. Commun. 55 (2019) 10820-10843. https://doi.org/10.1039/c9cc03813b.

[41] S. Arunachalam, E.M. Domingues, R. Das, J. Nauruzbayeva, U. Buttner, A. Syed, H. Mishra, Rendering SiO2/Si surfaces omniphobic by carving gas-entrapping microtextures comprising reentrant and doubly reentrant cavities or pillars, J. Vis. Exp. 2020 (2020) 1-16.

https://doi.org/10.3791/60403.

[42] V. Rontu, V. Jokinen, S. Franssila, Scalable Superomniphobic Surfaces, J. Microelectromechanical Syst. 29 (2020) 54-61. https://doi.org/10.1109/JMEMS.2019.2950769.

[43] N. Kodihalli Shivaprakash, J. Zhang, A. Panwar, C. Barry, Q. Truong, J. Mead, Continuous manufacturing of reentrant structures via roll-to-roll process, J. Appl. Polym. Sci. 136 (2019) 1-8. https://doi.org/10.1002/app.46980.

[44] N. Kodihalli Shivaprakash, T. Ferraguto, A. Panwar, S.S. Banerjee, C.F. Barry, J. Mead, Fabrication of Flexible Polymer Molds for Polymer Microstructuring by Roll-to-Roll Hot Embossing, ACS Omega. 4 (2019) 12480-12488. https://doi.org/10.1021/acsomega.9b01468.

[45] N. Kodihalli Shivaprakash, J. Zhang, T. Nahum, C. Barry, Q. Truong, J. Mead, Roll-to-roll hot embossing of high aspect ratio micro pillars for superhydrophobic applications, Int. Polym. Process. 34 (2019) 502-512. https://doi.org/10.3139/217.3815.

[46] J. Noh, J.H. Lee, S. Na, H. Lim, D.H. Jung, Fabrication of hierarchically micro-and nanostructured mold surfaces using laser ablation for mass production of superhydrophobic surfaces, Jpn. J. Appl. Phys. 49 (2010) 1065021-1065026. https://doi.org/10.1143/JJAP.49.106502.

[47] I. Gibson, D. Rosen, B. Stucker, Additive manufacturing technologies: 3D printing, rapid prototyping, and direct digital manufacturing, second edition, 2015. https://doi.org/10.1007/978-1-4939-2113-3.

[48] M. Hofmann, 3D printing gets a boost and opportunities with polymer materials, ACS Macro 
Lett. 3 (2014) 382-386. https://doi.org/10.1021/mz4006556.

[49] H.F. Shieh, R.W. Jennings, Three-dimensional printing of external airway splints for tracheomalacia, J. Thorac. Dis. 9 (2017) 414-416. https://doi.org/10.21037/jtd.2017.02.53.

[50] D. Bourell, J.P. Kruth, M. Leu, G. Levy, D. Rosen, A.M. Beese, A. Clare, Materials for additive manufacturing, CIRP Ann. - Manuf. Technol. 66 (2017) 659-681. https://doi.org/10.1016/j.cirp.2017.05.009.

[51] O. Tricinci, T. Terencio, B. Mazzolai, N.M. Pugno, F. Greco, V. Mattoli, 3D Micropatterned Surface Inspired by Salvinia molesta via Direct Laser Lithography, ACS Appl. Mater. Interfaces. 7 (2015) 25560-25567. https://doi.org/10.1021/acsami.5b07722.

[52] R. Melnikova, A. Ehrmann, K. Finsterbusch, 3D printing of textile-based structures by Fused Deposition Modelling (FDM) with different polymer materials, IOP Conf. Ser. Mater. Sci. Eng. 62 (2014) 012018. https://doi.org/10.1088/1757-899X/62/1/012018.

[53] R. Matsuzaki, M. Ueda, M. Namiki, T.-K. Jeong, H. Asahara, K. Horiguchi, T. Nakamura, A. Todoroki, Y. Hirano, Three-dimensional printing of continuous-fiber composites by in-nozzle impregnation, Sci. Rep. 6 (2016) 23058. https://doi.org/10.1038/srep23058.

[54] T.D. Ngo, A. Kashani, G. Imbalzano, K.T.Q. Nguyen, D. Hui, Additive manufacturing (3D printing): A review of materials, methods, applications and challenges, Compos. Part B Eng. 143 (2018) 172-196. https://doi.org/10.1016/j.compositesb.2018.02.012.

[55] M. von Übel, The 3D Printing Materials Guide | All3DP, (2019). https://all3dp.com/1/3dprinting-materials-guide-3d-printer-material/ (accessed June 9, 2020).

[56] F.F. Craig, The reservoir engineering aspects of waterflooding., New York, U.S.a., Am. Inst. Min. Met. Pet. Engrs. Inc., 1971. 3 of the H (1971).

[57] R.N. Wenzel, Resistance of solid surfaces to wetting by water, Ind. Eng. Chem. 28 (1936) $988-$ 994. https://doi.org/10.1021/ie50320a024.

[58] A.B.D. Cassie, S. Baxter, Wettability of porous surfaces, Trans. Faraday Soc. 40 (1944) 546. https://doi.org/10.1039/tf9444000546.

[59] D.M. Mattox, Learn more about Surface Energy Substrate ("Real ") Surfaces and Surface Modification, Handb. Phys. Vap. Depos. Process. 2 (2010).

[60] Galileo, Discorso intorno alle Cose che Stanno in su l'Acqua, 1st ed., Florence, 1612. https://galileo.ou.edu/exhibits/discourse-floating-bodies.

[61] S. Banerjee, Simple derivation of Young, Wenzel and Cassie-Baxter equations and its interpretations, (2008) 1-10. http://arxiv.org/abs/0808.1460.

[62] X. Xu, X. Wang, Derivation of the Wenzel and Cassie Equations from a Phase Field Model for Two Phase Flow on Rough Surface, SIAM J. Appl. Math. 70 (2010) 2929-2941. https://doi.org/10.1137/090775828.

[63] R.J. Good, A Thermodynamic Derivation of Wenzel's Modification of Young's Equation for Contact Angles; Together with a Theory of Hysteresis, J. Am. Chem. Soc. 74 (1952) 50415042. https://doi.org/10.1021/ja01140a014.

[64] K. Seo, M. Kim, D.H. Kim, Re-derivation of Young's Equation, Wenzel Equation, and CassieBaxter Equation Based on Energy Minimization, Surf. Energy. (2015). 
https://doi.org/10.5772/61066.

[65] F.E. Bartell, J.W. Shepard, Surface roughness as related to hysteresis of contact angles. II. The systems paraffin-3 molar calcium chloride solution-air and paraffin-glycerol-air, J. Phys. Chem. 57 (1953) 455-458. https://doi.org/10.1021/j150505a015.

[66] L. Gao, T.J. McCarthy, Contact angle hysteresis explained, Langmuir. 22 (2006) 6234-6237. https://doi.org/10.1021/la060254j.

[67] G. Whyman, E. Bormashenko, T. Stein, The rigorous derivation of Young, Cassie-Baxter and Wenzel equations and the analysis of the contact angle hysteresis phenomenon, Chem. Phys. Lett. 450 (2008) 355-359. https://doi.org/10.1016/j.cplett.2007.11.033.

[68] Y.Q. Zu, Y.Y. Yan, J.Q. Li, Z.W. Han, Wetting behaviours of a single droplet on biomimetic micro structured surfaces, J. Bionic Eng. 7 (2010) 191-198. https://doi.org/10.1016/S16726529(09)60202-X.

[69] E. Bormashenko, General equation describing wetting of rough surfaces, J. Colloid Interface Sci. 360 (2011) 317-319. https://doi.org/10.1016/j.jcis.2011.04.051.

[70] M.A. Rodríguez-Valverde, Mechanical derivation of the Wenzel and Cassie equations using a statistical interpretation of drop dispensation, J. Colloid Interface Sci. 327 (2008) 477-479. https://doi.org/10.1016/j.jcis.2008.08.048.

[71] K.J. Kubiak, M.C.T. Wilson, T.G. Mathia, P. Carval, Wettability versus roughness of engineering surfaces, Wear. 271 (2011) 523-528. https://doi.org/10.1016/j.wear.2010.03.029.

[72] ASTM International, ASTM D7334-08: Standard practice for surface wettability of coatings, substrates and pigments by advancing contact angle measurement: active standard, Am. Soc. Test. Mater. 08 (2013) 1-3. https://doi.org/10.1520/D7334-08R13.2.

[73] X. Zhang, F. Shi, J. Niu, Y. Jiang, Z. Wang, Superhydrophobic surfaces: From structural control to functional application, J. Mater. Chem. 18 (2008) 621-633. https://doi.org/10.1039/b711226b.

[74] Z.Z. Gu, H. Uetsuka, K. Takahashi, R. Nakajima, H. Onishi, A. Fujishima, O. Sato, Structural color and the lotus effect, Angew. Chemie - Int. Ed. 42 (2003) 894-897. https://doi.org/10.1002/anie.200390235.

[75] E. Hosono, S. Fujihara, I. Honma, H. Zhou, Superhydrophobic perpendicular nanopin film by the bottom-up process, J. Am. Chem. Soc. 127 (2005) 13458-13459. https://doi.org/10.1021/ja053745j.

[76] Z. Guo, F. Zhou, J. Hao, W. Liu, Stable biomimetic super-hydrophobic engineering materials, J. Am. Chem. Soc. 127 (2005) 15670-15671. https://doi.org/10.1021/ja0547836.

[77] L. Gao, T.J. McCarthy, A perfectly hydrophobic surface $\left(\theta A / \theta R=180^{\circ} / 180^{\circ}\right)$, J. Am. Chem. Soc. 128 (2006) 9052-9053. https://doi.org/10.1021/ja062943n.

[78] N.K. Andersen, R. Taboryski, Drop shape analysis for determination of dynamic contact angles by double sided elliptical fitting method, Meas. Sci. Technol. 28 (2017).

https://doi.org/10.1088/1361-6501/aa5dcf.

[79] Z.N. Xu, S.Y. Wang, A highly accurate dynamic contact angle algorithm for drops on inclined surface based on ellipse-fitting, Rev. Sci. Instrum. 86 (2015). 
https://doi.org/10.1063/1.4906506.

[80] M. Taylor, A.J. Urquhart, M. Zelzer, M.C. Davies, M.R. Alexander, Picoliter water contact angle measurement on polymers, Langmuir. 23 (2007) 6875-6878.

https://doi.org/10.1021/la070100j.

[81] S. Do Hong, M.Y. Ha, S. Balachandar, Static and dynamic contact angles of water droplet on a solid surface using molecular dynamics simulation, J. Colloid Interface Sci. 339 (2009) 187195. https://doi.org/10.1016/j.jcis.2009.07.048.

[82] H. Zhang, Y. Zhao, R. Lv, C. Yang, Freezing of sessile water droplet for various contact angles, Int. J. Therm. Sci. 101 (2016) 59-67. https://doi.org/10.1016/j.ijthermalsci.2015.10.027.

[83] J. Mo, J. Sha, D. Li, Z. Li, Y. Chen, Fluid release pressure for nanochannels: The Young-Laplace equation using the effective contact angle, Nanoscale. 11 (2019) 8408-8415.

https://doi.org/10.1039/c8nr08987f.

[84] D. Biolè, M. Wang, V. Bertola, Assessment of direct image processing methods to measure the apparent contact angle of liquid drops, Exp. Therm. Fluid Sci. 76 (2016) 296-305. https://doi.org/10.1016/j.expthermflusci.2016.04.006.

[85] Z. Xu, An exact model based dynamic contact angle algorithm, Meas. J. Int. Meas. Confed. 129 (2018) 611-624. https://doi.org/10.1016/j.measurement.2018.07.082.

[86] V. Nežerka, M. Somr, J. Trejbal, Contact Angle Measurement Tool Based on Image Analysis, Exp. Tech. 42 (2018) 271-278. https://doi.org/10.1007/s40799-017-0231-0.

[87] Y. Saulick, S.D.N. Lourenço, B.A. Baudet, A Semi-Automated Technique for Repeatable and Reproducible Contact Angle Measurements in Granular Materials using the Sessile Drop Method, Soil Sci. Soc. Am. J. 81 (2017) 241-249. https://doi.org/10.2136/sssaj2016.04.0131.

[88] F. Thomsen, Measuring with method - but which one?, Krus. Tech. Note. 49 (2008) 1-4.

[89] K. Ellinas, Superhydrophobic and superamphiphobic smart surfaces, Elsevier Inc., 2020. https://doi.org/10.1016/b978-0-12-849870-5.00015-x.

[90] M. Tuominen, H. Teisala, J. Haapanen, J.M. Mäkelä, M. Honkanen, M. Vippola, S. Bardage, M.E.P. Wålinder, A. Swerin, Superamphiphobic overhang structured coating on a biobased material, Appl. Surf. Sci. 389 (2016) 135-143. https://doi.org/10.1016/j.apsusc.2016.05.095.

[91] A. Thomas, N. V. Priezjev, Molecular dynamics simulation study of a polymer droplet transport over an array of spherical nanoparticles, (2020). http://arxiv.org/abs/2002.11602.

[92] H. Yin, M.S. Moghaddam, M. Wålinder, A. Swerin, Fabrication of Superamphiphobic Wood Surface Based on Silicone Nanofilaments, in: Proc. 15th Annu. Meet. North. Eur. Netw. Wood Sci. Eng., Lund, Sweden, 2019: pp. 135-137. http://kth.divaportal.org/smash/record.jsf?pid=diva2\%3A1417597\&dswid=-2153.

[93] L. Afferrante, G. Carbone, Microstructured superhydrorepellent surfaces: Effect of drop pressure on fakir-state stability and apparent contact angles, J. Phys. Condens. Matter. 22 (2010). https://doi.org/10.1088/0953-8984/22/32/325107.

[94] Y. Jiang, W. Xu, M.A. Sarshar, C.H. Choi, Generalized models for advancing and receding contact angles of fakir droplets on pillared and pored surfaces, J. Colloid Interface Sci. 552 (2019) 359-371. https://doi.org/10.1016/j.jcis.2019.05.053. 
[95] S. Chemistry, Fakir droplets Nanoscale plasticity, Nature. 1 (2002) 14-15.

[96] B. Bhushan, E.K. Her, Fabrication of superhydrophobic surfaces with high and low adhesion inspired from rose petal, Langmuir. 26 (2010) 8207-8217. https://doi.org/10.1021/la904585j.

[97] G. Gong, J. Wu, X. Jin, L. Jiang, Adhesion Tuning at Superhydrophobic States: From Petal Effect to Lotus Effect, Macromol. Mater. Eng. 300 (2015) 1057-1062. https://doi.org/10.1002/mame.201500143.

[98] S.H. Park, S. Lee, D. Moreira, P.R. Bandaru, I. Han, D.J. Yun, Bioinspired superhydrophobic surfaces, fabricated through simple and scalable roll-to-roll processing, Sci. Rep. 5 (2015) 1-9. https://doi.org/10.1038/srep15430.

[99] C. Neinhuis, W. Barthlott, Characterization and distribution of water-repellent, self-cleaning plant surfaces, Ann. Bot. 79 (1997) 667-677. https://doi.org/10.1006/anbo.1997.0400.

[100] T. Nishino, M. Meguro, K. Nakamae, M. Matsushita, Y. Ueda, The lowest surface free energy based on -CF3 alignment, Langmuir. 15 (1999) 4321-4323. https://doi.org/10.1021/la981727s.

[101] T. Darmanin, F. Guittard, Superhydrophobic and superoleophobic properties in nature, Mater. Today. 18 (2015) 273-285. https://doi.org/10.1016/j.mattod.2015.01.001.

[102] G.T. Yun, W. Bin Jung, M.S. Oh, G.M. Jang, J. Baek, N.I. Kim, S.G. Im, H.T. Jung, Springtailinspired superomniphobic surface with extreme pressure resistance, Sci. Adv. 4 (2018). https://doi.org/10.1126/sciadv.aat4978.

[103] Y. Yang, X. Li, X. Zheng, Z. Chen, Q. Zhou, Y. Chen, 3D-Printed Biomimetic Super-Hydrophobic Structure for Microdroplet Manipulation and Oil/Water Separation, Adv. Mater. 30 (2018) 111. https://doi.org/10.1002/adma.201704912.

[104] Q. Wang, Z. Dong, X. Yan, Y. Chang, L. Ren, J. Zhou, Biomimetic Hydrophobic Surfaces with Low or High Adhesion Based on Poly(vinyl alcohol) and SiO2 Nanoparticles, J. Bionic Eng. 14 (2017) 476-485. https://doi.org/10.1016/S1672-6529(16)60413-4.

[105] G.S. Watson, D.W. Green, B.W. Cribb, C.L. Brown, C.R. Meritt, M.J. Tobin, J. Vongsvivut, M. Sun, A.P. Liang, J.A. Watson, Insect Analogue to the Lotus Leaf: A Planthopper Wing Membrane Incorporating a Low-Adhesion, Nonwetting, Superhydrophobic, Bactericidal, and Biocompatible Surface, ACS Appl. Mater. Interfaces. 9 (2017) 24381-24392. https://doi.org/10.1021/acsami.7b08368.

[106] P. Liu, Y. Gao, F. Wang, J. Yang, X. Yu, W. Zhang, L. Yang, Superhydrophobic and self-cleaning behavior of Portland cement with lotus-leaf-like microstructure, J. Clean. Prod. 156 (2017) 775-785. https://doi.org/10.1016/j.jclepro.2017.03.211.

[107] K. Koch, B. Bhushan, W. Barthlott, Multifunctional surface structures of plants: An inspiration for biomimetics, Prog. Mater. Sci. 54 (2009) 137-178. https://doi.org/10.1016/j.pmatsci.2008.07.003.

[108] Y.T. Cheng, D.E. Rodak, C.A. Wong, C.A. Hayden, Effects of micro- and nano-structures on the self-cleaning behaviour of lotus leaves, Nanotechnology. 17 (2006) 1359-1362. https://doi.org/10.1088/0957-4484/17/5/032.

[109] M.A. Samaha, H.V. Tafreshi, M. Gad-el-Hak, Superhydrophobic surfaces: From the lotus leaf to the submarine, Comptes Rendus - Mec. 340 (2012) 18-34. 
https://doi.org/10.1016/j.crme.2011.11.002.

[110] Y. Liu, H. Gu, Y. Jia, J. Liu, H. Zhang, R. Wang, B. Zhang, H. Zhang, Q. Zhang, Design and preparation of biomimetic polydimethylsiloxane (PDMS) films with superhydrophobic, selfhealing and drag reduction properties via replication of shark skin and SI-ATRP, Chem. Eng. J. 356 (2019) 318-328. https://doi.org/10.1016/j.cej.2018.09.022.

[111] K.M.T. Ahmmed, J. Montagut, A.M. Kietzig, Drag on superhydrophobic sharkskin inspired surface in a closed channel turbulent flow, Can. J. Chem. Eng. 95 (2017) 1934-1942. https://doi.org/10.1002/cjce.22850.

[112] D. Zhao, Q. Tian, M. Wang, Y. Jin, Study on the hydrophobic property of shark-skin-inspired micro-riblets, J. Bionic Eng. 11 (2014) 296-302. https://doi.org/10.1016/S16726529(14)60046-9.

[113] K. Liu, J. Du, J. Wu, L. Jiang, Superhydrophobic gecko feet with high adhesive forces towards water and their bio-inspired materials, Nanoscale. 4 (2012) 768-772.

https://doi.org/10.1039/C1NR11369K.

[114] G.S. Watson, D.W. Green, L. Schwarzkopf, X. Li, B.W. Cribb, S. Myhra, J.A. Watson, A gecko skin micro/nano structure - A low adhesion, superhydrophobic, anti-wetting, self-cleaning, biocompatible, antibacterial surface, Acta Biomater. 21 (2015) 109-122. https://doi.org/10.1016/j.actbio.2015.03.007.

[115] Y. Wang, H. Lai, Z. Cheng, H. Zhang, E. Zhang, T. Lv, Y. Liu, L. Jiang, Gecko toe pads inspired: In situ switchable superhydrophobic shape memory adhesive film, Nanoscale. 11 (2019) 89848993. https://doi.org/10.1039/c9nr00154a.

[116] Y. Zhang, S. Qu, X. Cheng, X. Gao, X. Guo, Fabrication and Characterization of Gecko-inspired Dry Adhesion, Superhydrophobicity and Wet Self-cleaning Surfaces, J. Bionic Eng. 13 (2016) 132-142. https://doi.org/10.1016/S1672-6529(14)60167-0.

[117] X. Lu, H. Cai, Y. Wu, C. Teng, C. Jiang, Y. Zhu, L. Jiang, Peach skin effect: a quasisuperhydrophobic state with high adhesive force, Sci. Bull. 60 (2015) 453-459. https://doi.org/10.1007/s11434-014-0725-4.

[118] D. Han, A.J. Steckl, Superhydrophobic and oleophobic fibers by coaxial electrospinning, Langmuir. 25 (2009) 9454-9462. https://doi.org/10.1021/la900660v.

[119] U. Stachewicz, R.J. Bailey, H. Zhang, C.A. Stone, C.R. Willis, A.H. Barber, Wetting Hierarchy in Oleophobic 3D Electrospun Nanofiber Networks, ACS Appl. Mater. Interfaces. 7 (2015) 16645-16652. https://doi.org/10.1021/acsami.5b04272.

[120] A. Tuteja, W. Choi, J.M. Mabry, G.H. McKinley, R.E. Cohen, Designing Superoleophobic Surfaces, 2007 AIChE Annu. Meet. (2007) 1618-1623.

[121] S. Pan, A.K. Kota, J.M. Mabry, A. Tuteja, Superomniphobic surfaces for effective chemical shielding, J. Am. Chem. Soc. 135 (2013) 578-581. https://doi.org/10.1021/ja310517s.

[122] L. Chen, Z. Guo, W. Liu, Outmatching superhydrophobicity: Bio-inspired re-entrant curvature for mighty superamphiphobicity in air, J. Mater. Chem. A. 5 (2017) 14480-14507. https://doi.org/10.1039/c7ta03248j.

[123] R. Hensel, R. Helbig, S. Aland, H.G. Braun, A. Voigt, C. Neinhuis, C. Werner, Wetting resistance at its topographical limit: The benefit of mushroom and serif T structures, Langmuir. 29 
(2013) 1100-1112. https://doi.org/10.1021/la304179b.

[124] A. Ahuja, J.A. Taylor, V. Lifton, A.A. Sidorenko, T.R. Salamon, E.J. Lobaton, P. Kolodner, T.N. Krupenkin, Nanonails: A simple geometrical approach to electrically tunable superlyophobic surfaces, Langmuir. 24 (2008) 9-14. https://doi.org/10.1021/la702327z.

[125] S.M. Kang, S.M. Kim, H.N. Kim, M.K. Kwak, D.H. Tahk, K.Y. Suh, Robust superomniphobic surfaces with mushroom-like micropillar arrays, Soft Matter. 8 (2012) 8563-8568. https://doi.org/10.1039/c2sm25879j.

[126] A. Cavalli, P. Boggild, F. Okkels, Parametric optimization of inverse trapezoid oleophobic surfaces, Langmuir. 28 (2012) 17545-17551. https://doi.org/10.1021/la303853g.

[127] L. Cao, H.A. Hu, D. Gao, Design and fabrication of micro-textures for inducing a superhydrophobic behavior on hydrophilic materials, Langmuir. 23 (2007) 4310-4314. https://doi.org/10.1021/la063572r.

[128] T. Wu, Y. Suzuki, Design, microfabrication and evaluation of robust high-performance superlyophobic surfaces, Sensors Actuators, B Chem. 156 (2011) 401-409. https://doi.org/10.1016/j.snb.2011.04.065.

[129] D. Liao, H. Qiu, Droplet dynamics on nanostructured doubly reentrant surfaces, Proc. World Congr. New Technol. 0 (2019) 1-5. https://doi.org/10.11159/icnfa19.155.

[130] E.M. Domingues, S. Arunachalam, J. Nauruzbayeva, H. Mishra, Biomimetic coating-free surfaces for long-term entrapment of air under wetting liquids, Nat. Commun. 9 (2018) 1-11. https://doi.org/10.1038/s41467-018-05895-x.

[131] J. Pacifico, K. Endo, S. Morgan, P. Mulvaney, Superhydrophobic effects of self-assembled monolayers on micropatterned surfaces: 3-D arrays mimicking the Lotus Leaf, Langmuir. 22 (2006) 11072-11076. https://doi.org/10.1021/la060925d.

[132] S.M. Lee, T.H. Kwon, Effects of intrinsic hydrophobicity on wettability of polymer replicas of a superhydrophobic lotus leaf, J. Micromechanics Microengineering. 17 (2007) 687-692. https://doi.org/10.1088/0960-1317/17/4/003.

[133] H. Choi, S. Choo, J. Shin, K. Kim, H. Lee, Fabrication of Superhydrophobic and Oleophobic Surfaces with Overhang Structure by Reverse Nanoimprint Lithography, 24359 (2013).

[134] W. Yao, L. Li, O.L. Li, Y.W. Cho, M.Y. Jeong, Y.R. Cho, Robust, self-cleaning, amphiphobic coating with flower-like nanostructure on micro-patterned polymer substrate, Chem. Eng. J. 352 (2018) 173-181. https://doi.org/10.1016/j.cej.2018.07.001.

[135] F.M.M. Reis, P. Lavieille, S. Blanco, M. Miscevic, ON THE EFFECT OF THE CONTACT ANGLE HYSTERESIS FOR SMALL DROPLETS ON A WETTABILITY GRADIENT SURFACE, Interfacial Phenom. Heat Transf. 4 (2016) 81-91. https://doi.org/10.1615/InterfacPhenomHeatTransfer.2017017460.

[136] S.N. Gorb, Functional surfaces in biology, 2009. https://doi.org/10.1007/978-1-4020-6697-9.

[137] E. V. Skorb, D. V. Andreeva, Layer-by-Layer approaches for formation of smart self-healing materials, Polym. Chem. 4 (2013) 4834-4845. https://doi.org/10.1039/c3py00088e.

[138] A.M. Fainleib, O.H. Purikova, Self-healing polymers: approaches of healing and their application, Polym. J. 41 (2019) 4-18. https://doi.org/10.15407/polymerj.41.01.004. 
[139] X. Gou, Z. Guo, Surface topographies of biomimetic superamphiphobic materials: design criteria, fabrication and performance, Adv. Colloid Interface Sci. 269 (2019) 87-121. https://doi.org/10.1016/j.cis.2019.04.007.

[140] R. Jafari, C. Cloutier, A. Allahdini, G. Momen, Recent progress and challenges with 3D printing of patterned hydrophobic and superhydrophobic surfaces, Int. J. Adv. Manuf. Technol. 103 (2019) 1225-1238. https://doi.org/10.1007/s00170-019-03630-4.

[141] C. Yan, P. Jiang, X. Jia, X. Wang, 3D printing of bioinspired textured surfaces with superamphiphobicity, Nanoscale. 12 (2020) 2924-2938. https://doi.org/10.1039/C9NR09620E.

[142] K.-S. Lee, R.H. Kim, D.-Y. Yang, S.H. Park, Advances in 3D nano/microfabrication using twophoton initiated polymerization, Prog. Polym. Sci. 33 (2008) 631-681. https://doi.org/10.1016/j.progpolymsci.2008.01.001.

[143] S.C. Ligon, R. Liska, J. Stampfl, M. Gurr, R. Mülhaupt, Polymers for 3D Printing and Customized Additive Manufacturing, Chem. Rev. 117 (2017) 10212-10290. https://doi.org/10.1021/acs.chemrev.7b00074.

[144] J.P. Kruth, Material Incress Manufacturing by Rapid Prototyping Techniques, CIRP Ann. Manuf. Technol. 40 (1991) 603-614. https://doi.org/10.1016/S0007-8506(07)61136-6.

[145] M.A. Azad, D. Olawuni, G. Kimbell, A.Z.M. Badruddoza, M.S. Hossain, T. Sultana, Polymers for Extrusion-Based 3D Printing of Pharmaceuticals: A Holistic Materials-Process Perspective, Pharmaceutics. 12 (2020) 124. https://doi.org/10.3390/pharmaceutics12020124.

[146] R. Anandkumar, S.R. Babu, FDM filaments with unique segmentation since evolution: a critical review, Prog. Addit. Manuf. 4 (2019) 185-193. https://doi.org/10.1007/s40964-0180069-8.

[147] T. Finnes, T. Letcher, High Definition 3D Printing-Comparing SLA and FDM Printing Technologies, J. Undergrad. Res. 13 (2015) 3. http://openprairie.sdstate.edu/jurhttp://openprairie.sdstate.edu/jur/vol13/iss1/3HIGHDEFIN ITION3DPRINTING.

[148] J.F.B. Pereira, L.P.N. Rebelo, R.D. Rogers, J.A.P. Coutinho, M.G. Freire, Combining ionic liquids and polyethylene glycols to boost the hydrophobic-hydrophilic range of aqueous biphasic systems, Phys. Chem. Chem. Phys. 15 (2013) 19580. https://doi.org/10.1039/c3cp53701c.

[149] E. Hendrick, M. Frey, Increasing Surface Hydrophilicity in Poly ( Lactic Acid ) Electrospun Fibers by Addition of Pla-b-Peg Co-Polymers, (n.d.).

[150] S. Jasmee, G. Omar, N.A.B. Masripan, A.A. Kamarolzaman, A.S. Ashikin, F.C. Ani, Hydrophobicity performance of polyethylene terephthalate ( PET ) and thermoplastic polyurethane ( TPU ) with thermal effect Hydrophobicity performance of polyethylene terephthalate ( PET) and thermoplastic polyurethane ( TPU ) with thermal effect, (n.d.).

[151] B. XIONG, S. ZHU, Y. FAN, H. LI, M. SHI, Y. CAO, Hydrophobic Modification of Poly(Ethylene Terephthalate) with Epoxy-Modified Polysiloxane by Reactive Extrusion, J. Macromol. Sci. Part B. 51 (2012) 630-641. https://doi.org/10.1080/00222348.2011.609787.

[152] J. Du, L. Zhang, J. Dong, Y. Li, C. Xu, W. Gao, Preparation of Hydrophobic Nylon Fabric, (n.d.).

[153] R. de Vries, A. Stell, S. Mohammed, C. Hermanns, A.H. Martinez, M. Jetten, A. van Apeldoorn, 
Bioengineering, biomaterials, and $\beta$-cell replacement therapy, in: Transplantation, Bioeng. Regen. Endocr. Pancreas, Elsevier, 2020: pp. 461-486. https://doi.org/10.1016/B978-0-12814831-0.00033-6.

[154] E. Sirjani, P.J. Cragg, M.K. Dymond, Glass transition temperatures, melting temperatures, water contact angles and dimensional precision of simple fused deposition model 3D prints and 3D printed channels constructed from a range of commercially available filaments, Chem. Data Collect. 22 (2019) 100244. https://doi.org/10.1016/j.cdc.2019.100244.

[155] Y. Tao, H. Wang, Z. Li, P. Li, S.Q. Shi, Development and Application of Wood Flour-Filled Polylactic Acid Composite Filament for 3D Printing, Materials (Basel). 10 (2017) 339. https://doi.org/10.3390/ma10040339.

[156] A. Zulfi, M.M. Munir, D.A. Hapidin, A. Rajak, D. Edikresnha, F. Iskandar, K. Khairurrijal, Air filtration media from electrospun waste high-impact polystyrene fiber membrane, Mater. Res. Express. 5 (2018) 035049. https://doi.org/10.1088/2053-1591/aab6ef.

[157] Y. Shi, Y. Sun, Z. Wang, Super-hydrophobic and super-oleophilic surface based on high-density polyethylene/waste ground rubber tire powder thermoplastic elastomer, J. Thermoplast. Compos. Mater. 33 (2020) 851-864. https://doi.org/10.1177/0892705718815542.

[158] B.S. Yilbas, M. Khaled, N. Abu-Dheir, N. Al-Aqeeli, S.A.M. Said, A.O.M. Ahmed, K.K. Varanasi, Y.K. Toumi, Wetting and other physical characteristics of polycarbonate surface textured using laser ablation, Appl. Surf. Sci. 320 (2014) 21-29.

https://doi.org/10.1016/j.apsusc.2014.09.052.

[159] Y. Qi, T. Chen, J. Zhang, A facile method of hydrophobic surface modification for acrylonitrilestyrene-acrylate terpolymer based on the out-migration property of metallic soaps, Appl. Surf. Sci. 435 (2018) 503-511. https://doi.org/10.1016/j.apsusc.2017.11.132.

[160] S. Knaus, A. Nennadal, Surface modification of polypropylene: Hydrophilic finishing with carbohydrates, Macromol. Symp. 127 (1998) 257-263. https://doi.org/10.1002/masy.19981270133.

[161] R.B. Seymour, C.E. Carraher, Structure-Property Relationships in Polymers, Springer US, Boston, MA, 1984. https://doi.org/10.1007/978-1-4684-4748-4.

[162] J. Ko, K. Cho, S.W. Han, H.K. Sung, S.W. Baek, W.-G. Koh, J.S. Yoon, Hydrophilic surface modification of poly(methyl methacrylate)-based ocular prostheses using poly(ethylene glycol) grafting, Colloids Surfaces B Biointerfaces. 158 (2017) 287-294. https://doi.org/10.1016/j.colsurfb.2017.07.017.

[163] L.D. Paolinelli, A. Rashedi, J. Yao, M. Singer, Study of water wetting and water layer thickness in oil-water flow in horizontal pipes with different wettability, Chem. Eng. Sci. 183 (2018) 200-214. https://doi.org/10.1016/j.ces.2018.03.023.

[164] V. Leminen, S.-S. Ovaska, P. Tanninen, J. Varis, Convertability and Oil Resistance of Paperboard with Hydroxypropyl-Cellulose-Based Dispersion Barrier Coatings, J. Appl. Packag. Res. 7 (2015) 6.

[165] M. Teodorescu, M. Bercea, Poly(vinylpyrrolidone) - A Versatile Polymer for Biomedical and Beyond Medical Applications, Polym. Plast. Technol. Eng. 54 (2015) 923-943. https://doi.org/10.1080/03602559.2014.979506.

[166] J.M. Barrios, P.E. Romero, Improvement of Surface Roughness and Hydrophobicity in PETG 
Parts Manufactured via Fused Deposition Modeling (FDM): An Application in 3D Printed SelfCleaning Parts, Materials (Basel). 12 (2019) 2499. https://doi.org/10.3390/ma12152499.

[167] K.S. Boparai, R. Singh, Advances in Fused Deposition Modeling, Ref. Modul. Mater. Sci. Mater. Eng. (2017) 1-10. https://doi.org/10.1016/b978-0-12-803581-8.04166-7.

[168] M.E.A. PAPON, A. HAQUE, M.A.R. SHARIF, Effect of Nozzle Geometry on Melt Flow Simulation and Structural Property of Thermoplastic Nanocomposites in Fused Deposition Modeling, in: Am. Soc. Compos. 2017, DEStech Publications, Inc., Lancaster, PA, 2017: pp. 2167-2182. https://doi.org/10.12783/asc2017/15339.

[169] M. Livesu, S. Ellero, J. Martínez, S. Lefebvre, M. Attene, From 3D models to 3D prints: an overview of the processing pipeline, Comput. Graph. Forum. 36 (2017) 537-564. https://doi.org/10.1111/cgf.13147.

[170] M. Barahman, A.M. Lyons, Ratchetlike slip angle anisotropy on printed superhydrophobic surfaces, Langmuir. 27 (2011) 9902-9909. https://doi.org/10.1021/la201222a.

[171] Z. He, Y. Chen, J. Yang, C. Tang, J. Lv, Y. Liu, J. Mei, W. ming Lau, D. Hui, Fabrication of Polydimethylsiloxane films with special surface wettability by 3D printing, Compos. Part B Eng. 129 (2017) 58-65. https://doi.org/10.1016/j.compositesb.2017.07.025.

[172] J. Lv, Z. Gong, Z. He, J. Yang, Y. Chen, C. Tang, Y. Liu, M. Fan, W. Lau, 3D printing of a mechanically durable superhydrophobic porous membrane for oil-water separation, (2017) 12435-12444. https://doi.org/10.1039/c7ta02202f.

[173] X. Li, H. Shan, W. Zhang, B. Li, 3D printed robust superhydrophilic and underwater superoleophobic composite membrane for high efficient oil/water separation, Sep. Purif. Technol. 237 (2020) 116324. https://doi.org/10.1016/j.seppur.2019.116324.

[174] J.H. Shin, J. Heo, S. Jeon, J.H. Park, S. Kim, Bio-inspired hollow PDMS sponge for enhanced oil - water separation, J. Hazard. Mater. 365 (2019) 494-501. https://doi.org/10.1016/j.jhazmat.2018.10.078.

[175] A. Subramaniam, S. Sethuraman, Biomedical Applications of Nondegradable Polymers, Elsevier Inc., 2014. https://doi.org/10.1016/B978-0-12-396983-5.00019-3.

[176] B. Kang, J. Sung, H. So, Realization of Superhydrophobic Surfaces Based on Three-Dimensional Printing Technology, Int. J. Precis. Eng. Manuf. - Green Technol. (2019). https://doi.org/10.1007/s40684-019-00163-9.

[177] B. Kang, J. Hyeon, H. So, Facile microfabrication of 3-dimensional (3D) hydrophobic polymer surfaces using 3D printing technology, Appl. Surf. Sci. 499 (2020) 143733. https://doi.org/10.1016/j.apsusc.2019.143733.

[178] A. Milionis, C. Noyes, E. Loth, I.S. Bayer, Superhydrophobic 3D printed surfaces by dipcoating, Tech. Proc. 2014 NSTI Nanotechnol. Conf. Expo, NSTI-Nanotech 2014.2 (2014) 157160.

[179] K.M. Lee, H. Park, J. Kim, D.M. Chun, Fabrication of a superhydrophobic surface using a fused deposition modeling (FDM) 3D printer with poly lactic acid (PLA) filament and dip coating with silica nanoparticles, Appl. Surf. Sci. 467-468 (2019) 979-991.

https://doi.org/10.1016/j.apsusc.2018.10.205.

[180] J.L. M.J. Cook, J. H. Johnston, Anisotropic Wetting Behaviour of Modified 3D Printed Micro- 
Structured Polymer Surfaces for Water Harvesting School of Chemical and Physical Sciences, Victoria University of Wellington, (2017) 295-297. 
2021-01-06

\section{Realizing surface amphiphobicity using 3D printing techniques: A critical move towards manufacturing low-cost reentrant geometries}

Shams, Hamza

Elsevier

Shams H, Basit K, Khan MA, et al., (2021) Realizing surface amphiphobicity using 3D printing techniques: A critical move towards manufacturing low-cost reentrant geometries. Additive Manufacturing, Volume 38, February 2021, Article number 101777

https://doi.org/10.1016/j.addma.2020.101777

Downloaded from Cranfield Library Services E-Repository 